Discussion Paper No. 18-024

\title{
The effects of uncertainty
} on market liquidity:

\section{Evidence from Hurricane Sandy}

Dominik Rehse, Ryan Riordan, Nico Rottke, and Joachim Zietz

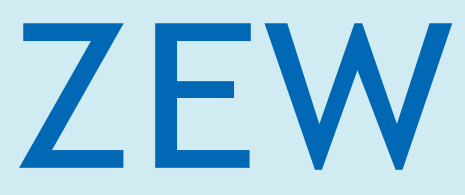

Zentrum für Europäische Wirtschaftsforschung $\mathrm{GmbH}$

Centre for European

Economic Research 


\title{
Discussion Paper No. 18-024 \\ The effects of uncertainty on market liquidity: Evidence from Hurricane Sandy
}

\author{
Dominik Rehse, Ryan Riordan, Nico Rottke, \\ and Joachim Zietz
}

Download this ZEW Discussion Paper from our ftp server:

http://ftp.zew.de/pub/zew-docs/dp/dp18024.pdf

Die Discussion Papers dienen einer möglichst schnellen Verbreitung von neueren Forschungsarbeiten des ZEW. Die Beiträge liegen in alleiniger Verantwortung der Autoren und stellen nicht notwendigerweise die Meinung des ZEW dar.

Discussion Papers are intended to make results of ZEW research promptly available to other economists in order to encourage discussion and suggestions for revisions. The authors are solely responsible for the contents which do not necessarily represent the opinion of the ZEW. 


\title{
The effects of uncertainty on market liquidity: Evidence from Hurricane Sandy
}

\author{
Dominik Rehse ${ }^{1}$, Ryan Riordan ${ }^{2}$, Nico Rottke $^{3}$, Joachim Zietz ${ }^{4}$
}

April 26, 2018

\begin{abstract}
We test the effects of uncertainty on market liquidity using Hurricane Sandy as a natural experiment. Given the unprecedented strength, scale and nature of the storm, the potential damages of a landfall near the Greater New York area were unpredictable and therefore uncertain. Using a difference-in-differences setting, we compare the market reactions of Real Estate Investment Trusts (REITs) with and without properties in the widely-published evacuation zone of New York City prior to landfall. We find relatively less trading and wider bid-ask spreads in affected REITs. The results confirm theory on the detrimental effects of uncertainty on market functioning.
\end{abstract}

JEL classification: G12, G14

Keywords: Uncertainty, liquidity, financial crisis, natural experiment

Corresponding author: Dominik Rehse, dominik.rehse@zew.de. Affiliations: ${ }^{1}$ Centre for European Economic Research (ZEW), ${ }^{2}$ Queen's University, ${ }^{3}$ aamundo, ${ }^{4}$ EBS Business School. 


\section{Introduction}

One of the most startling observations during the financial crisis of 2007 and 2008 was the decrease in trading volume for a large group of assets. Although prices for mortgage-backed securities, credit derivatives and thinly-traded assets were still quoted regularly, little trading took place at those prices. Such market freezes are difficult to reconcile with standard economic theory, according to which market prices are equilibrium outcomes of supply and demand and should adjust to changes in the expected cash flows of a given assets within a relatively short period of time. Therefore, while prices adjust, trading volume should remain largely unchanged.

Recent theoretical work suggests that uncertainty or ambiguity aversion might provide an explanation for this drop in trading volume. Easley and O'Hara (2010) use Bewley's (2002) model of Knightian uncertainty to model a market with traders that have incomplete preferences over portfolios. The traders change their portfolio allocation only if expected utility is higher for all beliefs in the set of a trader's beliefs. As uncertainty increases, traders are increasingly unable to decide which portfolio they prefer over another, i.e. whether a portfolio reallocation would in fact lead to an increase in expected utility. In these models the difficulty in rank-ordering alternative portfolios leads to a drop in trading volume. However, they still quote bid and ask prices. These prices refer to those prices which would allow traders to improve their rank-ordering in the light of uncertainty. The increase in the spread between bid and ask prices is referred to by Easley and O'Hara (2010) as the uncertainty spread. Other theoretical work by Ozsoylev and Werner (2011) and Routledge and Zin (2009) suggest a similar drop in trading volume and a widening of bid-ask spreads in the face of uncertainty. Ozsoylev and Werner (2011) model a market in which informed traders receive a private signal that resolves ambiguity about an asset's payoff. Under random supply of this assets, uninformed arbitrageurs choose not to trade in a rational expectations equilibrium, which leads to a drop in trading volume. Routledge and Zin (2009) model a market in which an ambiguity-averse market maker sets bid and ask prices for a derivative. Given uncertainty about the probability distribution of the payoff of the derivative's underlying and rigidities in the market maker's hedging ability, the market maker widens her bid-ask spread to reduce the likelihood of trading. In these models a reduction in trading volume leads to lower welfare as gains from trade are not realized as they would be with lower uncertainty. Quantifying these welfare losses in an empirical setting is an important step towards understanding the real-world importance of uncertainty. In summary, this line of theoretical work implies that an asset's trading volume drops and traders trading this asset widen bid-ask spreads with increasing uncertainty.

We provide a quasi-experimental test of uncertainty on trading in financial markets. In the week from Monday, October 22 to Friday, October 26, 2012, Hurricane Sandy developed from a depression in the Caribbean to a threat to the population of the Greater New York area. Due to the 
unprecedented strength, scale, path, and nature of the storm, the potential and damages of a landfall were highly uncertain. During this week, trading at the exchanges in New York City continued as usual. This allows us to compare trading volume and bid-ask spreads of REITs with property in the widely-published evacuation zone of New York City (i.e. affected by uncertainty) with the respective liquidity measures of REITs without property in the affected area (i.e. not affected by uncertainty) before and after the uncertainty. The first group of REITs constitutes the treatment group, the second group the control group. By jointly using both cross-sectional variation as well as variation over time in a difference-in-differences setting, we can isolate the effect of uncertainty on trading volume and bid-ask spreads from most sources of confounding variation. We address concerns of simultaneous increases in the market price of risk and in information asymmetries between market participants in two ways. First, we show that neither measures of risk nor measures of information asymmetries are higher for treated stocks than for control stocks in the week prior to Hurricane Sandy's landfall. Second, we include these proxy variables as control variables in all regression specifications. $^{1}$

We find both statistically significant and economically large effects of uncertainty on trading volume. A REIT with a portfolio allocation of 10 percent in the evacuation zone of New York City had a 16 to 31 percent lower trading volume than a REIT without property in the evacuation zone. The exact magnitudes depend on the specification of the treatment and the control groups. With an average portfolio allocation in the evacuation zone of about 4 percent for the treatment group, this represents an Average Treatment Effect on the Treated (ATT) of 7 to 12 percent. Assuming that all of the decreases in trading represent lost gains from trade means that a large number of investors that would have traded without uncertainty held portfolios that they may have preferred not to hold. The uncertainty impairs the market participants' ability to effectively share risk.

We also find that uncertainty widens bid-ask spreads, as predicted by theory. The results for closing bid-ask spreads are stronger than for average intraday bid-ask spreads. Both are in the same direction and statistically significant, however. If the spread is just a transfer from liquidity suppliers to liquidity demanders, the welfare effects are ambiguous. If the widened spread led to less trading due to increased opportunity costs, then this can also lead to lower welfare. The volume results show, that fewer gains from trade are realized during periods of uncertainty. Coupled with wider spreads, this suggests that overall welfare may be lower. In the natural experiment described here, the uncertainty was not man-made and as such there was no policy response available to reduce this type of uncertainty. However, this example highlights the importance of avoiding uncertainty where feasible.

Overall, the results shed light on the economic losses associated with uncertainty and their potential magnitude, particularly in terms of risk-sharing. We take the results as confirmatory empirical evidence of the detrimental

\footnotetext{
${ }^{1}$ The results do not change much when including these control variables.
} 
effects of uncertainty on market liquidity as theorized by Easley and O'Hara (2010), Ozsoylev and Werner (2011) and Routledge and Zin (2009).

This paper contributes to two strands of the literature. First, we add to the literature on the determinants of market liquidity in general and stock liquidity in particular. Vayanos and Wang (2013) provide a comprehensive summary of this stream of the literature. One of the main empirical observations in this context is the co-movement of market liquidity of different assets. Uncertainty shocks may be one determinant of this co-movement. At the micro level, uncertainty shocks such as the one studied in this paper might lead to co-movement of market liquidity at the level of individual stocks. At the macro level, broader uncertainty shocks such as the financial crisis of 2007 and 2008 may well lead to co-movement in market liquidity at a stock market-wide level. As we argue later, such effects are difficult to isolate from simultaneous changes to other determinants of market liquidity. However, uncertainty may well be an additional determinant of market-wide liquidity commonality, as studied for instance in Chung and Chuwonganant (2014) and Karolyi et al. (2012). In this respect, this paper also contributes to the stream of the literature that is concerned with the broader economic consequences of uncertainty shocks. Bloom (2014) provides a survey of this literature.

We proceed as follows. We first introduce the theoretical implications tested in this paper. We then outline our identification strategy. This includes a description of the quasi-experimental setup of the week prior to Hurricane Sandy's landfall, a description of the dataset, details on the specification of the treatment and control groups, the specification of the model as well as a discussion of whether we are identifying the consequences of an uncertainty or a risk shock. The results and various robustness checks are presented in the following two sections. In the last section of this paper, we conclude and outline potential areas for further research.

\section{Tested theoretical implications}

This section describes the theoretical models related to this paper. Easley and O'Hara's (2010) models traders with incomplete preferences over portfolios that rank-order them according to the portfolios' expected utility. One portfolio is preferred over another only if it has greater expected utility for each element of a trader's set of beliefs. This rank-ordering can lead to ties and Easley and O'Hara (2010) supplement the theory with the "inertia" assumption introduced in Bewley (2002). Traders change their individual portfolios only if it leads to greater expected utility for every element of a trader's set of beliefs. This implies that traders reduce trading in the wake of uncertainty when they have difficulties to rank-order alternative portfolio allocations. If uncertainty suddenly increases, traders essentially "freeze" their portfolios at the stage before the increase in uncertainty. Despite the resulting drop in trading volume, traders are generally still willing to trade and post bid and ask prices. The quoted prices relate to prices which would 
allow traders to improve their rank-ordering and to overcome their trading "inertia". The resulting uncertainty spreads are distinct from the asymmetric information spreads commonly studied in the market microstructure literature. The theory is also distinct from other market imperfections related to market liquidity, such as participation and transaction costs, imperfect competition, funding constraints as well as search costs. ${ }^{2}$

A model by Ozsoylev and Werner (2011) also yields similar implications of an inverse relationship between uncertainty and trading volume. They model a market with risk-averse informed traders, risk-neutral competitive arbitrageurs and a risky asset. Informed traders receive a private signal that resolves ambiguity about the asset's payoff, while arbitrageurs do not observe the signal. Ozsoylev and Werner (2011) show that under random supply of the asset, arbitrageurs choose not to trade in a rational expectations equilibrium, resulting in a drop in trading volume.

Another model by Routledge and Zin (2009), in turn, yields the prediction of an inverse relationship between uncertainty and bid-ask spreads. In their model, an ambiguity-averse market maker sets bid and ask prices for a derivative and faces random buy and sell orders. There is uncertainty about the probability distribution of the payoff for the derivative's underlying and the market maker can trade this underlying to partially hedge her derivative position. Routledge and Zin (2009) show that in cases of a rigidity in the market maker's hedging ability, she widens bid-ask spreads to reduce the likelihood of further derivative trades.

In summary, these theoretical models have two main implications:

Implication 1 Trading volume decreases with uncertainty.

Implication 2 Bid-ask spreads increase with uncertainty.

\section{$3 \quad$ Identification strategy}

Testing these theoretical implications is challenging since uncertainty shocks are rare, many of them have no clear beginning or end and they usually co-occur with other events. Three ideal experimental setups would allow a clear-cut identification of the effects of uncertainty on trading volume and spreads:

1. Trading of two (or more) assets is observed cross-sectionally, with one asset being affected by an uncertainty shock (treatment) and one asset not (control). The effect of the "uncertainty treatment" could then be determined by calculating the cross-sectional difference in trading volume and spreads ("simple differences" to determine "between variation"). The critical identifying assumption is that trading volume and spreads are the same in the absence of treatment, i.e. all other determinants are the same.

\footnotetext{
${ }^{2}$ Vayanos and Wang (2013) provide a comprehensive review of the alternative determinants of market liquidity.
} 
2. Trading of one (or more) assets is observed before and during (or during and after) an uncertainty shock. The effect of the uncertainty treatment could then be determined by calculating the difference in trading volume and spreads over time ("simple differences" to determine "within variation"). The two critical identifying assumptions are that all other determinants of trading volume and spreads remain unchanged around this uncertainty shock and that any pre-treatment trend in the outcome variable of interest is removed when calculating the differences over time.

3. Both previous setups combined. In this setting, the effect of the uncertainty treatment could be determined in two steps ("difference in differences"): First, for both treatment and control asset, the difference in trading volume and spreads before and during (or during and after) the uncertainty shock is calculated. Second, the resulting differences are then differenced again between the treatment and the control asset(s). By taking this double-difference approach, the setup does not need the identifying assumptions of the first setup and only the second identifying assumption of the second setup. In this case, the trendassumption implies that the treatment and the control asset(s) have the same trend in the outcome variable of interest before (or after) the uncertainty treatment, commonly referred to as the "parallel trends" assumption.

The third experimental setup is particularly attractive, as it addresses both cross-sectional confounding variation, such as non-comparable treatment and control assets, as well as confounding variation over time, such as cooccurrence of shocks to trading volume and spreads other than uncertainty shocks.

In practice, the main difficulty lies in finding assets and the respective uncertainty shocks that come sufficiently close to these ideals. For instance, the uncertainty about the fair value of mortgage-backed securities at the beginning of the financial crisis did affect all mortgage-backed securities at once. Identification of the treatment effect would be possible if all other determinants of trading outcomes would have stayed the same (second experimental setup), which is not the case however. Most prominently, shocks to the funding structure of market participants coincided with the uncertainty shock at the beginning of the crisis (Brunnermeier, 2009), making the identification of the effect of interest virtually impossible.

In this paper, we use location information on the properties of REITs, which are listed property investment firms, to identify stocks that can be expected to be affected by damages due to Hurricane Sandy. We identify a set of REITs with property in the well-published evacuation zone of New York City and compare their trading volume and bid-ask spreads in the week prior to the landfall of Sandy with REIT stocks without properties in the affected area. In the following, we describe the setting of Hurricane Sandy as well as the treatment effect estimation approach in more detail. 


\subsection{Setting of natural experiment}

\subsubsection{Trading week before Hurricane Sandy made landfall}

Hurricane Sandy was the strongest Hurricane of the 2012 season. Formed in the Caribbean, declared a tropical storm on Monday, October 22, and a Hurricane on Wednesday, October 24, by the United States National Hurricane Center (NHC). Sandy made landfall near Kingston, Jamaica as a Category 2 hurricane on the same day and near Santiago de Cuba, Cuba, as a Category 3 hurricane on the following day. Both countries were severely affected by damages and disruptions due to the storm. In Jamaica, about 70 percent of the country's population was without power, airports were closed and authorities mandated a 48-hour curfew. In Cuba, damages were particularly severe in Santiago de Cuba, where more than 15,000 homes were destroyed and more than 100,000 homes were damaged. Sandy's outer bands also caused many deaths and damages in neighboring countries, particularly Haiti, where more than 50 people were killed and food shortages and wide-ranging damages hit a country that still had not fully recovered from the 2010 earthquake. These dramatic developments were widely reported in the media and raised interest in the projected path of the storm. Figure 1 illustrates the increasing news coverage of Hurricane Sandy during this time period with the number of articles mentioning the hurricane in the LexisNexis database.

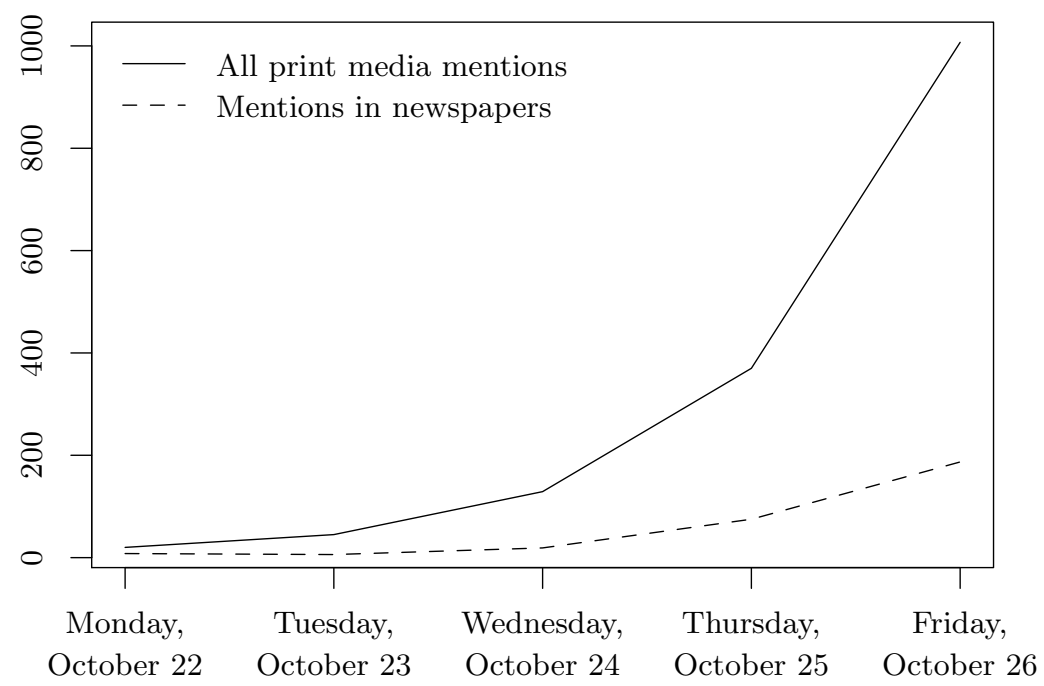

Figure 1: Number of media mentions of Hurricane Sandy in Lexis Nexis

The period between Monday, October 22, and Sunday, October 28, 2012 corresponds to the seven days before Hurricane Sandy made landfall on October 29, 2012, i.e. the week of uncertainty.

Over the course of the trading week from Monday, October 22 to Friday, October 26, 2012 it became increasingly clear that Sandy might make landfall in the North-East of the United States and would not move east towards the open Atlantic Ocean, like most hurricanes. While the European 
Centre for Medium-Range Weather Forecasts (ECMWF) correctly predicted this development on Tuesday, October 23, 2012, the United States National Weather Service (NWS) and the NHC forecasted this path only towards the end of the trading week. Figure 2 shows the widely reported storm path maps by the NWS.

While other hurricanes had hit the North East of the United States before, the meteorological and hydrological setting of Hurricane Sandy was rare, if not unique: Tropical storms usually have a compact wind field that circles around a low-pressure center. Such storms draw their energy from the warm water of the tropical Atlantic Ocean. As Hurricane Sandy moved northwards, however, it merged with a weather system arriving from the west and became an extra-tropical storm, which differ in that they are fueled by sharp temperature differences between masses of warm and cool air. Extratropical storms also differ from tropical storms in that they have much larger and dispersed wind fields. In the case of Sandy, the wind fields retained much of the hurricane-force winds. In the media, this development lead to the imagery of "Frankenstorm" meeting his "bride", although later Hurricane Sandy was more often called "Superstorm". At the same time, the prediction of high tide at landfall suggested a combination of both coastal flooding and heavy rainfall. This created a setting which probably had not been observed since 1821 (Brandon et al., 2014).

Another unique feature of Hurricane Sandy was that it was expected to hit not only the Greater New York area and but also New York City, the most densely populated metropolitan area in the United States. While Hurricane Irene hit New York City in the previous year, leading to a redefinition of evacuation plans and emergency procedures, it was unclear whether these new measures would be sufficient to protect lives and to prevent severe damage to buildings, infrastructure and the local economy.

Overall, the uncertainty caused by Hurricane Sandy in the trading week from Monday, October 22 to Friday, October 26, 2012 had two main sources: First, the path of Hurricane Sandy was highly uncertain. While projections by the ECMWF showed that Sandy might well make landfall in the NorthEast, the NHC forecasts predicted such a path of the hurricane only later in the week. Second, the unprecedented nature and expected intensity of the storm had unforeseeable consequences for the Greater New York area and for the affected REITs in particular.

\subsubsection{Landfall of Hurricane Sandy}

The authorities of the State of New York and of New York City took the immediate threat very seriously. On Friday, October 26, 2012, New York's Governor Cuomo declared a statewide state of emergency. President Obama signed a pre-disaster declaration later that day. All airports, major tunnels and bridges as well as public transportation were suspended until the early morning of Monday, October 29, 2012, the day when Hurricane Sandy was expected to make landfall. Importantly, trading on the New York Stock Exchange (NYSE) was also suspended. Mayor Bloomberg also ordered the 


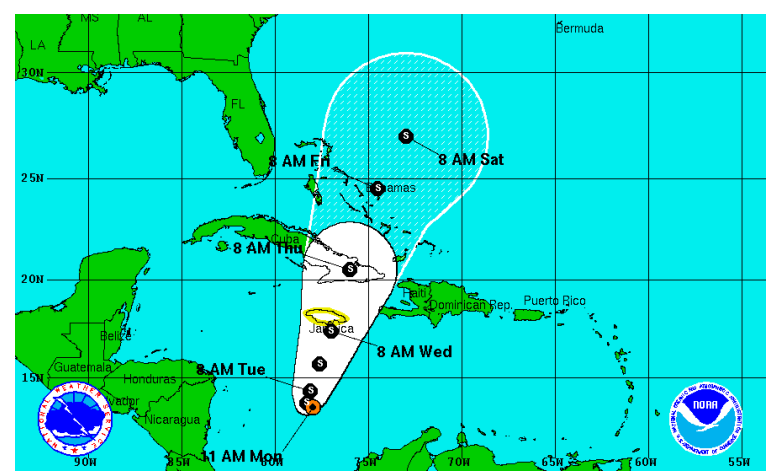

(a) Monday, October 22, 10am

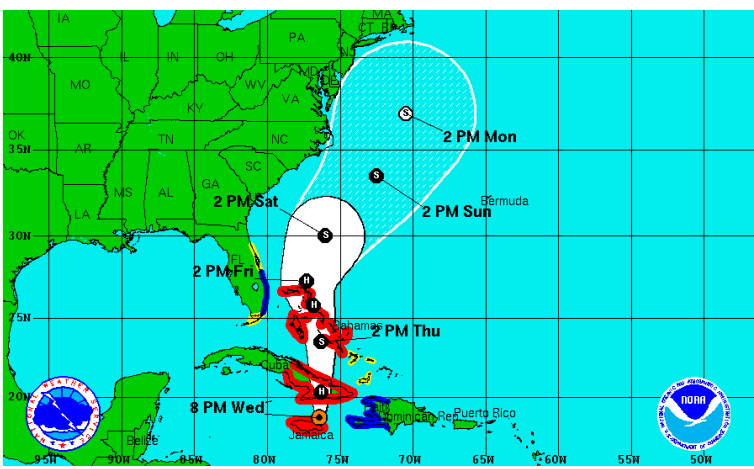

(c) Wednesday, October 24, $7 \mathrm{pm}$

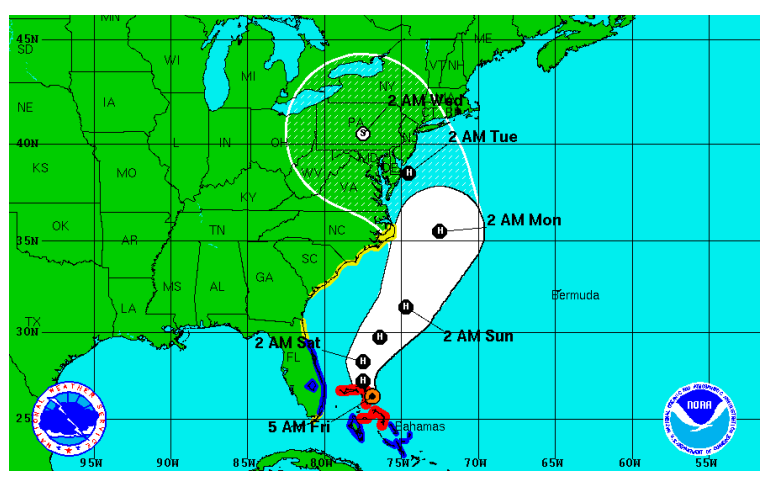

(e) Friday, October 26, 4am

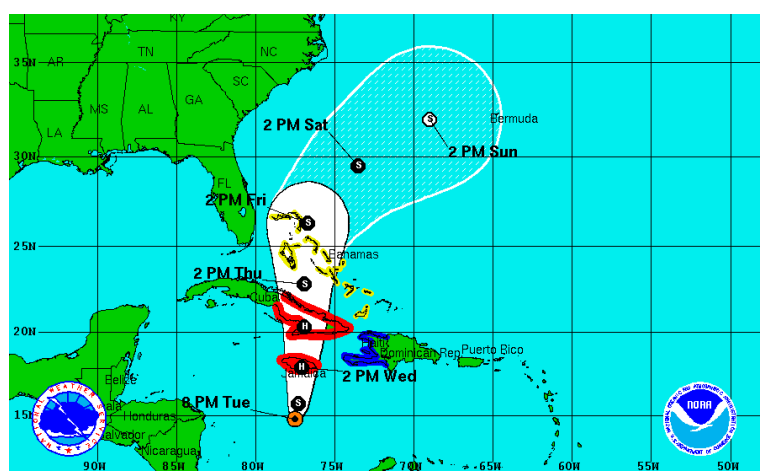

(b) Tuesday, October 23, $7 \mathrm{pm}$

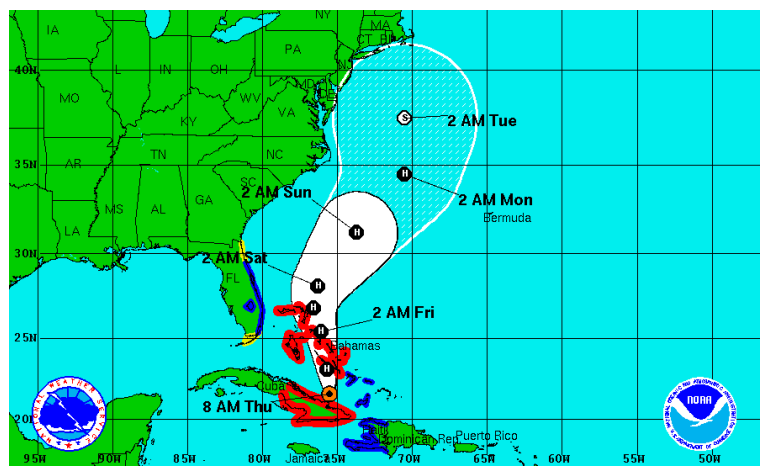

(d) Thursday, October 25, 7am

Figure 2: NHC track forecast cone for Hurricane Sandy

Colored coastal regions indicate NHC weather warnings: hurricane warning (red), hurricane watch (pink), tropical storm warning (blue) and tropical storm watch (yellow). Current position of center of cyclone is shown as an orange dot. Other dots in forecast cone indicate forecasted position of center at specific point in time. Dots are filled black if cyclone is expected to be tropical and white if cyclone is expected to be extra-tropical. Letters in dots indicate forecasted intensity: $\mathrm{D}=$ Tropical depression, $\mathrm{S}=$ tropical storm, $\mathrm{H}=$ hurricane, $\mathrm{M}=$ major hurricane. Solid white part of cone shows forecast for next three days, non-filled part of cone shows forecast for the following two days. Time information is presented in Eastern Standard Time (EST). 
Table 1: Chronology of Hurricane Sandy

Trading week before Hurricane Sandy made landfall

Monday, October 22

- Sandy is declared a tropical storm

Tuesday, October 23

- ECMWF predicts that Sandy will make landfall in the North-East of the United States

- NHC predicts that Sandy will turn East towards the North Atlantic

Wednesday, October 24

- Media reporting mostly focuses on NHC predictions

- Sandy is declared a hurricane

- Landfall near Kingston, Jamaica (Category 2)

- About 70 percent of Jamaican population is without power, airports are closed, 48-hour curfew

Thursday, October 25

- Landfall near Santiago de Cuba, Cuba (Category 3)

- Severe damage, particularly around Santiago de Cuba, with 15,000 homes destroyed and 100,000 homes damaged

- Sandy's outer bands affect neighboring countries, particularly Haiti

- Broad media coverage of damage

Friday, October 26

- Early in the morning, NHC revises predictions, indicating landfall in North East of United States

- Forecasted merger of tropical cyclone with weather system coming from the East is illustrated in the media as "Frankenstorm" meeting his "bride"

- Governor Cuomo declares statewide state of emergency, President Obama signs pre-disaster declaration

- Last trading day before Sandy makes landfall

Landfall of Hurricane Sandy

Saturday, October 27

- Mayor Bloomberg warns New Yorkers to prepare for arrival of Sandy and announces shutdown of public transportation starting on Sunday

Sunday, October 28

- Mayor Bloomberg orders evacuation of sub-evacuation zone A

- Most of public transportation suspended

Monday, October 29

- At around 8pm Sandy makes landfall near Atlantic City, New Jersey

- Severe flooding, power and gas outages

Tuesday, October 30

- Damage inspection, first respondent activities and rescue missions dominate media reports

- Exchanges remain closed

Trading week after Hurricane Sandy made landfall

Wednesday, October 30 to - Exchanges reopen on Wednesday morning, the first Friday, November 02 trading day after the landfall

- Wide-ranging recovery and reconstruction activities

- Public life gets restored step-by-step 
evacuation of the first part of the evacuation zone redefined after Hurricane Irene had hit New York City the previous year.

After Hurricane Sandy made landfall on the evening of Monday, October 29, 2012, the precautionary measures turned out to be more than necessary. Hurricane Sandy caused severe damages to the Greater New York area in general and New York City in particular. Severe floodings in many parts of the city, both overground and in tunnels underground, power and gas outages took their toll, several buildings and construction sites were damaged.

\subsubsection{Trading week after Hurricane Sandy made landfall}

Although schools remained closed for the entire week of Monday, October 29 to Friday, November 02, 2012 and the trading floor of the NYSE had been flooded, trading resumed on Wednesday 31. The two-day weather closure therefore separates the time before and after Hurricane Sandy made landfall. Table 1 provides an overview of the chronology of events.

\subsection{Description of dataset}

Our dataset consists of a sample of U.S. "equity" REITs, which primarily invest directly in the real estate market and which form the largest REIT subclass. ${ }^{3}$ REITs can be either privately traded or publicly listed. Our sample consists of publicly traded REITs on the NYSE, where the majority of the listed REITs are traded. REITs operate under a relatively strict regulatory framework, which real estate investment firms may apply for. Among other things, REITs are forced to pay out at least 90 percent of their taxable income in the form of dividends, at least 75 percent of a REIT's assets have to be invested in real estate and 75 percent of a REIT's gross income has to come from operating these properties. The main benefit of accepting the limitations of the REIT framework is that dividends are tax-deductible, which prevents double-taxation and grants REITs a beneficial tax status. Overall, REITs constitute a very homogeneous group of firms, which leaves the investment portfolio as the main differentiating factor across REITs.

Public equity REITs are very transparent concerning their investment portfolio. In their annual report, they provide detailed information on the properties they own, including addresses as well as book values. SNL records this information and also provides geo-coordinates for each recorded property, which allows matching with other geo-coded data, such as with the hurricane evacuation zone information outlined in the next section.

In compiling the dataset, we combine data on firm fundamentals and individual property portfolio information from SNL with daily trading data from CRSP and intraday trading data from the NYSE Daily Trade and Quote Database (DTAQ). We match all firms marked as REIT in CRSP and marked as equity REIT in SNL based on their CUSIP code. We use daily data from

\footnotetext{
${ }^{3}$ In contrast to "mortgage" REITs, which primarily invest in mortgage-backed securities and other debt-related financial instruments and "hybrid" REITs, which combine both investment styles.
} 
CRSP and drop observations for which the bid price exceeds the ask price, the average share price per quarter is below $1 \$$ (i.e. penny stocks), the data was not recorded on the primary exchange, exchange changes took place during the observation period, less than 30 daily observations per quarter or than 3 observations per week were available. Data from SNL is dropped if individual balance sheet items exceed the amount of total assets or total assets are unavailable. All variables calculated from SNL data are winsorized at the $5 \%$ and $95 \%$ level. We limit our sample to observations for 2012 , but account for time lags as defined later. ${ }^{4}$ After data cleaning and merging we are left with a balanced sample of 77 REITs. We then merge data from DTAQ to the firms in the sample using their CUSIP code.

Our dependent variables are the dollar volume of a stock as a measure of trading volume as well as three different measures of bid-ask spreads. We use CRSP data at daily frequency to determine the trading volume and the bid-ask spread at closing time of a given trading day. The variables are determined for each firm $i$ and trading day $d$ as follows:

$$
\begin{aligned}
& {\text { Dollar } \text { volume }_{i, d}=\text { No. of shares traded }}_{i, d} \cdot \text { Closing price }_{i, d}
\end{aligned}
$$

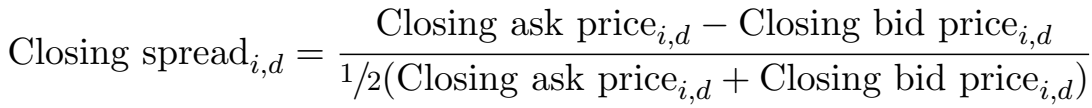

In order to address concerns about closing spreads from CRSP not being fully representative of bid-ask spreads over the course of a given trading day (for instance discussed in Chung and Zhang (2014)), we additionally calculate quoted spread and effective spread using DTAQ intraday data following Holden and Jacobsen (2014). We calculate them for each stock $i$ as follows:

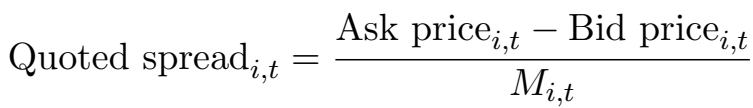

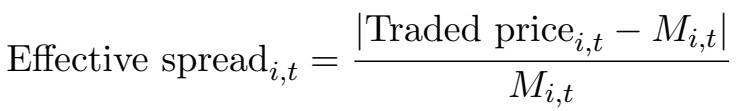

with midpoint price $M_{i, t}=1 / 2 \times\left(\right.$ Ask price $_{i, t}+$ Bid price $\left._{i, t}\right)$ and subscripts $t, d$ and $w$ denoting variables at intraday, daily and weekly frequency respectively. We incrementally aggregate the liquidity measures from intraday to daily frequency $(t \rightarrow d)$ and from daily to weekly frequency $(d \rightarrow w)$ by averaging. A high dollar volume indicates high market liquidity, while a high spread measure indicates low market liquidity.

Using data from SNL, CRSP and DTAQ, we also define a number of other variables that serve as proxies to compare the treated and non-treated REITs and as control variables. Most importantly, we use DTAQ data to calculate intraday volatility as a measure of risk and price impact as a measure of

\footnotetext{
${ }^{4}$ For a consistent presentation of the results, we also drop three firms which do not have data available for all weeks of 2012, but our results are not sensitive to this data restriction.
} 
information asymmetries between market participants as follows:

$$
\begin{aligned}
\text { Intraday volatility }_{i, d} & =\sqrt{\frac{1}{N-1} \sum_{t=o p e n}^{\text {close }}\left(R_{i, t}-\bar{R}\right)^{2}} \\
\text { Price impact }_{i, t} & =D_{i, t} \frac{M_{i, t+5 m i n}-M_{i, t}}{M_{i, t}}
\end{aligned}
$$

with $R_{i, t}$ denoting 5 -minute returns of the respective midpoint price $\left(M_{i, t}\right)$ and $D_{i, t}$ being +1 for buyer initiated trades and -1 for seller initiated trades. Intraday volatility is aggregated from daily to weekly frequency $(d \rightarrow w)$ by averaging; price impact is first aggregated to daily frequency $(t \rightarrow d)$ and subsequently to weekly frequency $(d \rightarrow w)$ by averaging as well. All remaining variable definitions are provided in subsection A.1.

Table 2 presents descriptive statistics for the whole year of 2012. All liquidity measures are right-tailed and approximatively log-normally distributed. The mean ${ }^{5}$ dollar volume for the whole year of 2012 was about $\$ 30.8 \mathrm{~m}$, with a standard deviation of about $\$ 40.8 \mathrm{~m}$, a minimum of $\$ 0.1 \mathrm{~m}$ and a maximum of $\$ 482.2 \mathrm{~m}$; the mean closing spread amounted to 7.7 basis points, with a standard deviation of 7.3 basis points, a minimum of 0.7 basis points and a maximum of 108.2 basis points; the mean quoted spread for 2012 was about 17.2 basis points, with a standard deviation of 33.1 basis points, a minimum of 2.1 basis points and a maximum of 486.7 basis points; the mean effective spread for 2012 was about 9.4 basis points, with a standard deviation of 8.7 basis points, a minimum of 1.9 basis points and a maximum of 79.1 basis points. For all further analyses, we use log-transformations of the respective liquidity measures.

\subsection{Specification of treatment intensity}

To identify the effects of uncertainty on trading volume and bid-ask spreads, the quasi-experimental setup described earlier requires a clear separation of those stocks that were affected by the uncertainty shock (treated stocks) and those that were not (control stocks). We base the separation of treatment and control firms on the definition of the evacuation zone of New York City. The evacuation zone was widely published by the media as well as on a dedicated website ${ }^{6}$ which allowed checking addresses of specific buildings for whether they were in the evacuation zone. At the time, three sub-evacuation zones - A, B and C, in order of decreasing danger of flooding - had been established. Detailed information on these zones was also available for download from the website of the City of New York in the form of Keyhole Markup Language (KML) files, which can be imported in a Geographical Information System (GIS). Using the "Wayback Machine" of the Internet Archive", we

\footnotetext{
${ }^{5}$ Due to the aggregation to weeks, an indicated mean value corresponds to the average of the weekly averages of a given liquidity measure.

${ }^{6}$ The most recent version of this website is available under the following URL: http://maps.nyc.gov/hurricane

${ }^{7}$ Accessible under the following URL: http://archive.org
} 


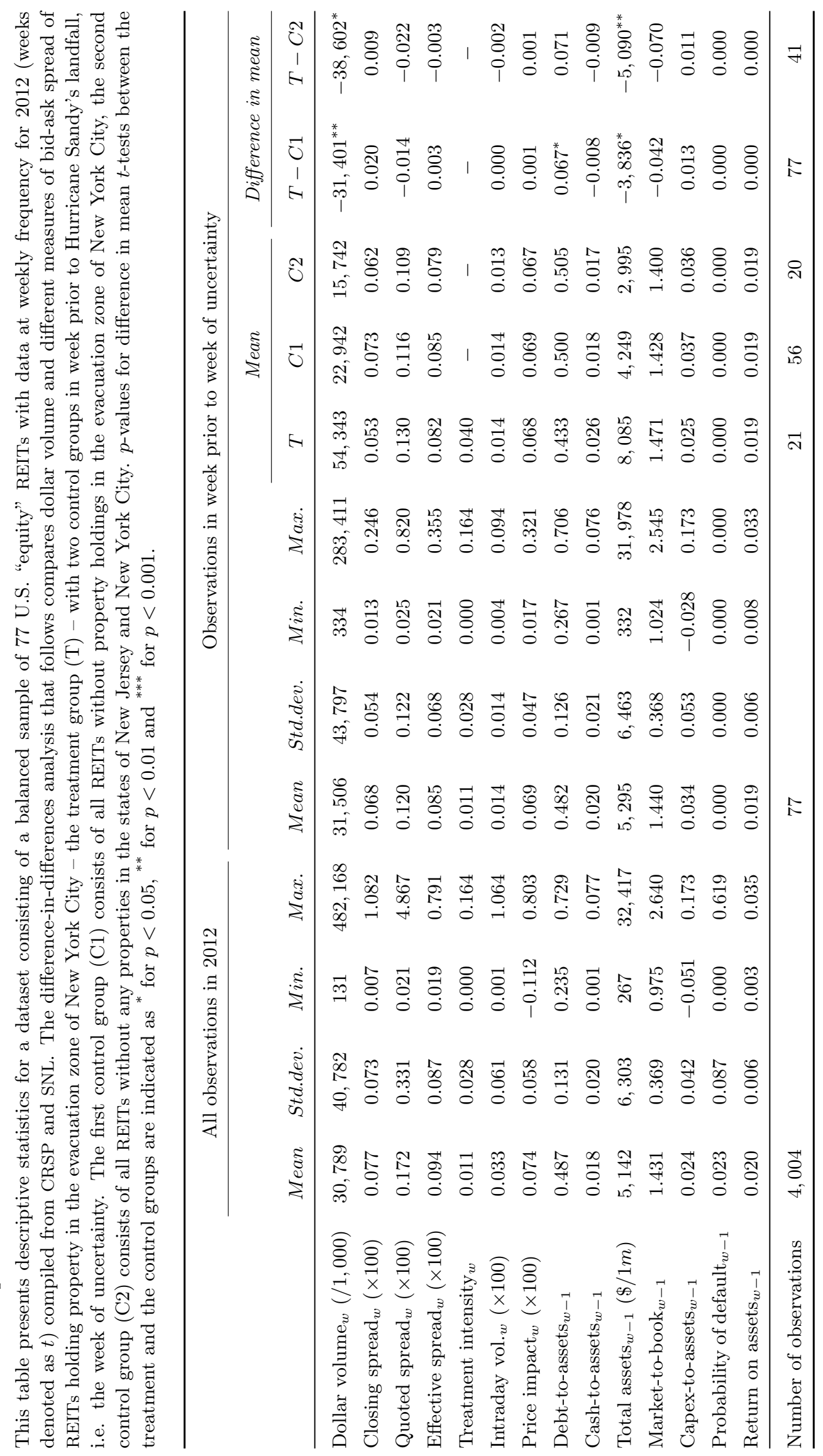


obtained the KML files as of November 20, 2011. This corresponds to the evacuation areas redefined after Hurricane Irene had hit New York City in August of $2011 .^{8}$

We define treated stocks as those stocks with property in one of the three evacuation zones. For this purpose, we match the geo-coded location of individual properties from SNL with the geo-information provided by the KML files using GIS software. We use data on individual property's book values from the end of 2011 as this is the last time period for which this information is widely available. Our treatment intensity variable is then defined as the percentage share of the book value of the properties located in the evacuation area. Figure 3 illustrates the distribution of properties in the Greater New York area in general and Manhattan in particular (see also Figure A.2.1). Out of the 77 REITs in our sample, 21 REITs had property in the evacuation zone. The share in total book value, i.e. the treatment intensity, ranges between 0.3 percent and 16.4 percent.

While other cities in New York and neighboring states were also potentially affected by Hurricane Sandy, the choice of New York City is attractive for three reasons. First, a significant part of the (professional) traders trading REITs is likely to be located in New York City or at least have to be considered knowledgeable of the area. Market participants were therefore likely to discriminate between firms with properties subject to storm damage and firms with a lower likelihood of property damage. Second, even if traders were not located in New York City, media reports concentrate on New York City when reporting from the Greater New York area. It is therefore likely that information on potential damages of Hurricane Sandy was more readily available for this area. Third, the information set provided by the City of New York on evacuation zones was much more detailed and was made more widely available than for other cities in the area.

The group of control stocks are defined in two different ways. The first control group (C1) includes all firms without any property in the evacuation zone of New York City. This applies to 56 REITs in the sample. While this approach maximizes the number of observations available for identifying the causal effect of interest, it has the disadvantage of including firms with properties in other areas potentially affected by Hurricane Sandy. The second control group (C2) therefore only includes those firms, which did not have any property in the states of New York and New Jersey. This group consists of 20 REITs. While Hurricane Sandy also caused damage in other states, the most severe damage had to be expected in potential flooding areas where the initial landfall would occur. Over the course of the week before Hurricane Sandy made landfall, it became more and more clear that Lower New York and New Jersey were likely to be the most affected areas.

The assignment mechanism underlying the above definition of the treatment group and the respective control groups is not completely random with

\footnotetext{
${ }^{8}$ Hurricane Irene had much less significant consequences for New York City than Hurricane Sandy, not only retrospectively but also in terms of the potential consequences before the storms made landfall.
} 


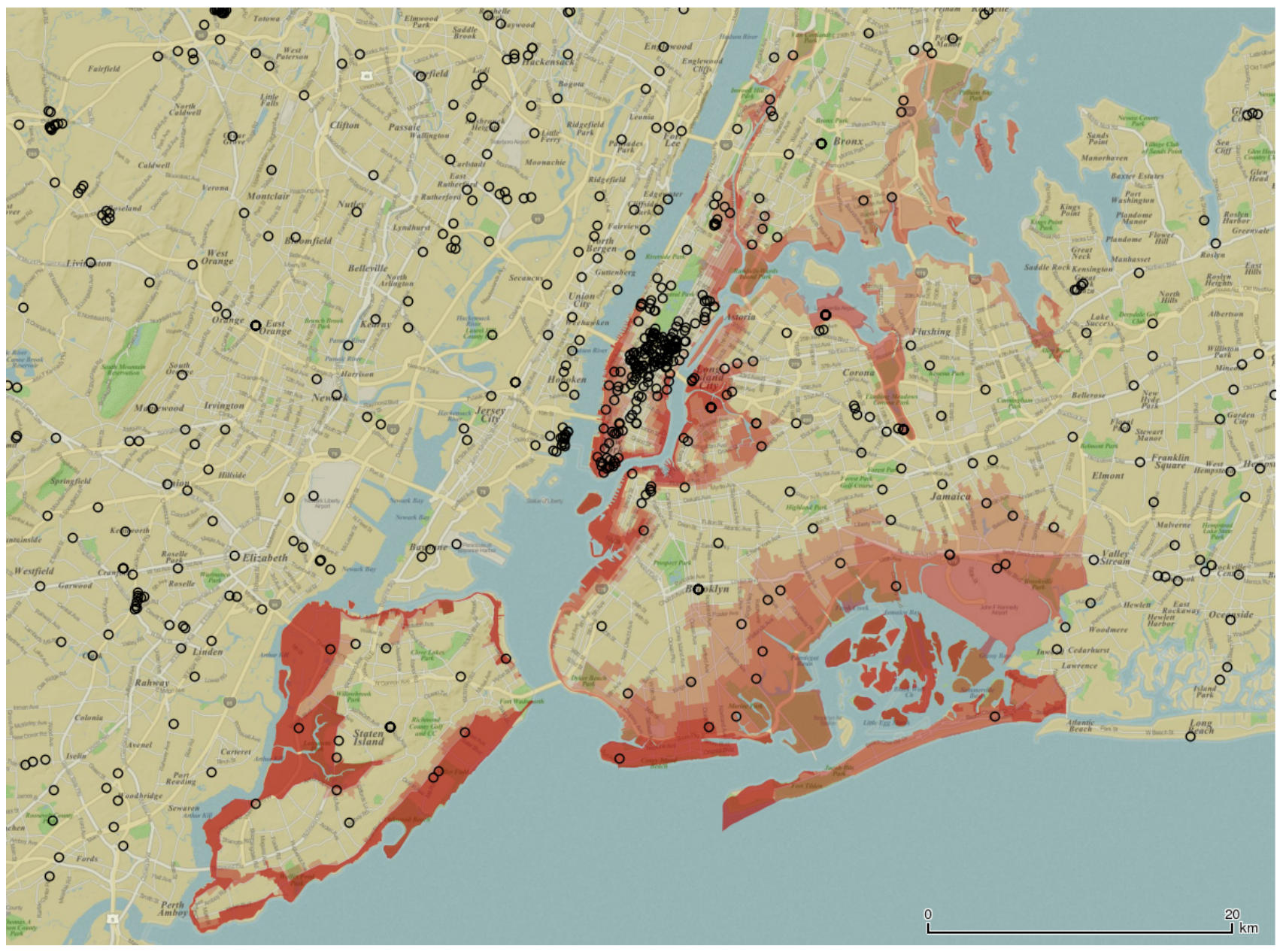

Figure 3: REIT properties in New York City

Individual properties are shown as black circles. The sub-evacuation zones are colored in red: Zone $\mathrm{A}$ in dark red, zone $\mathrm{B}$ in medium red, zone $\mathrm{C}$ in light red.

respect to the outcome variables of interest. This is due to the fact that the selection of the treatment units was based on geographical similarity. In turn, geographic similarity of firms has been shown to lead to co-movement in stock liquidity measures if a liquidity determinant is determined on a geographical level Bernile et al. (2015). In the difference-in-differences setup suggested in this paper, however, such confounding variation would have to occur in parallel to the uncertainty shock in the week prior to the landfall of Hurricane Sandy. In subsection 3.5 we discuss potential sources of confounding variation.

\subsection{Model specification}

The difference-in-differences specifications used for identification are similar in spirit to the specification suggested by Bertrand et al. (2004):

$$
\begin{array}{r}
\log \left(y_{i, w}\right)=\beta_{0} d_{w=43}+\beta_{1}\left(d_{w=43} \cdot T_{i}\right)+X_{i, w} Z+D_{i=j} \Gamma \\
+D_{w=u} \Delta+\epsilon_{i, w}
\end{array}
$$


where $i$ and $w$ index firms and weeks, $y_{i, w}$ denotes dollar volume or measures of the bid-ask spread, $d_{i}$ and $d_{w}$ are indicator variables identifying firms and weeks, $w=43$ denotes the week of uncertainty prior to Hurricane Sandy's landfall, $D_{i}$ and $D_{w}$ denote firm and time fixed effects, i.e. matrices of $d_{j}$ 's and $d_{u}$ 's using the first firm's identifier and the first week as base category $(j>1$ and $u>1$ ) and not containing the week prior to Hurricane Sandy's landfall $(u \neq 43) . T_{i}$ denotes the treatment intensity defined in the previous section. It is not separately included in the specification since it is time-fixed and is already captured by the firm-fixed effects $D_{i}$. The treatment group is defined as those $i$ for which $T_{i}>0$, the control group as those $i$ for which $T_{i}=0$. The effect of the week of uncertainty on the respective liquidity measures is given by $\beta_{1}$. $X_{i, w}$ contains additional control variables.

We further split up this net effect into an "initial treatment effect" and a "treatment reversal effect" with the following second specification:

$$
\begin{array}{r}
\log \left(y_{i, w}\right)=\beta_{0} d_{w>42}+\beta_{1} d_{w>43}+\beta_{2}\left(d_{w>42} \cdot T_{i}\right)+\beta_{3}\left(d_{w>43} \cdot T_{i}\right) \\
+X_{i, w} Z+D_{i=j} \Gamma+D_{w=u} \Delta+\epsilon_{i, w} .
\end{array}
$$

The respective uncertainty effects are then given by $\beta_{2}$ and $\beta_{3}$.

The firm fixed effects serve the purpose of controlling for pre-treatment differences in the respective liquidity measures and thereby implicitly holding all time-constant firm-specific determinants of stock liquidity fixed. This assumption is particularly reasonable for REITs, which - due to their regulatory regime - can change many aspects of their business only slowly and our sample period is short. We nevertheless include a set of control variables with time-varying firm-specific determinants of stock liquidity, which are further discussed in subsection 3.5 and section 5 .

The measurement effect of including firm fixed effects depends on the length of the pre-treatment sample period: With a rather short pre-treatment sample period, the treatment effect is measured relative to recent stock liquidity levels and to recent time-constant firm-specific determinants of stock liquidity. With a longer pre-treatment sample period, the treatment effect is measured relative to the longer-term stock liquidity levels and to longer-term firm-specific determinants of stock liquidity.

The choice of the post-treatment sample period hinges on a trade-off between having enough observations for identifying "treatment reversal effects" and not systematically causing endogeneity problems. Post-treatment observations are - by definition - endogenous with respect to the treatment. For instance, after Hurricane Sandy made landfall, asymmetric information on building repairs for the treatment group's property portfolios could lead to changes in the liquidity of the treatment group's stocks, which would overlay with the identification of the effects of uncertainty on stock liquidity. Given these considerations, we use a sample of all observations in 2012 until the fifth week after the week of uncertainty $(w \in[1,48])$ for our baseline regressions. Choosing all observations since the beginning of 2012 is consistent with the definition of the treatment variable $T_{i}$ for which we only have data for the end of 2011. In the robustness checks we further limit the 
sample to observations starting only 20 weeks prior to the week of uncertainty $(w \in[23,48], u>20)$. The post-treatment sample of five weeks (from $w=44$ to $w=48$ ) was chosen heuristically. However, our results also hold for longer post-treatment samples.

The time fixed effects serve the purpose of controlling for common variation in the respective liquidity measures, reducing the residual variance and thereby increasing the power of our statistical tests. Standard errors for all models are estimated conservatively, with standard errors independently clustered at the level of both firms and weeks (Cameron et al., 2011).

\subsection{Identification concerns}

\subsubsection{Actual uncertainty shock}

Before addressing possible confounding effects, it is important to clearly define uncertainty, to distinguish it from risk and to build a case, that the given setting allows to identify the effects of uncertainty. Both risk and uncertainty describe a situation in which information about a future state is limited. The main conceptual difference - in the understanding of the seminal work of Knight (1921) - is that risk is perceived to be the measurable part of this limited information, while uncertainty is perceived to be the immeasurable part. In probabilistic language, risk allows to define a distribution of potential outcomes while uncertainty does not allow to define such a distribution.

We argue that the information set available on the potential outcomes in the quasi-experiment studied here contains a significant uncertainty component. The first source of uncertainty lies in whether Hurricane Sandy would make landfall on the East Coast. Given the contradicting results of the (quantitative) forecasting models of the NHC and the ECMWF, for most parts of the trading week this potential outcome was at least very hard to quantify.

After this source of uncertainty became less important towards the end of the week, the second source of uncertainty came into play. The decisive question was whether and to which extent REIT properties in New York City's evacuation zone would be damaged. Although the Greater New York area did experience other hurricanes before, the nature and scale of Hurricane Sandy was beyond any recent experience. As described earlier, the last similar meteorological and hydrological setup was in 1821 (Brandon et al., 2014), when New York was smaller and without skyscrapers. Therefore, fully quantifying the potential outcomes was difficult. This left much room for uncertainty to play a role in market participants' trading decisions.

\subsubsection{Actual investor concerns}

To get a better grasp of whether market participants cared about the potential negative consequences of the storm, we test whether returns of REITs in the treatment group were lower relative to returns of REITs in the first control group. Figure 4 presents cumulative returns and cumulative abnormal 
returns in the two weeks prior to and in the week after Hurricane Sandy's landfall, averaged for REITs with treatment intensity $T_{i}>0$ and for REITs with $T_{i}=0$. While returns for both groups were almost indistinguishable on the trading days between Monday, October 15 and Friday, October 19, 2012, differences in returns accumulated over the week between Monday, October 22 and Friday, October 26, 2012, with returns being more negative for the treatment group. The stronger divergence on Thursday, October 25 and Friday 26, 2012 corresponds precisely with the time, when news reporting on Hurricane Sandy grew particularly strong (see Figure 1) and the NHC track forecast cone started to indicate an expected landfall around New York City (see Figure 2).

We also conduct a more formal analysis of these differences by regressing interaction terms of the treatment intensity measure $T_{i}$ and trading day indicator variables $d_{d}$ on returns and absolute returns, using daily return observations from CRSP between Monday, October 01 and Friday, November 02, 2012 in the following specification:

$$
\begin{array}{r}
y_{i, d}=\beta_{0}+\beta_{1}\left(d_{d=\text { Oct. } 22} \cdot T_{i}\right)+\beta_{1}\left(d_{d=\text { Oct. } 23}+\ldots\right. \\
+\beta_{8}\left(d_{d=\text { Nov. } 02} \cdot T_{i}\right)+\epsilon_{i, d},
\end{array}
$$

with $y_{i, d}$ denoting either returns $R_{i, d}$ or abnormal returns $A R_{i, d}$. The coefficients $\beta_{1}$ to $\beta_{7}$ indicate average differences in returns or abnormal returns relative to the baseline period between Monday, October 01 and Friday, October 19, 2012. The red line indicates Hurricane Sandy's landfall on October 29, 2012. Abnormal returns are calculated as $A R_{i, d}=R_{i, d}-\beta_{i} M_{d}$, with $\beta_{i}$ being estimated in $R_{i, d}=\alpha_{i}+\beta_{i} M_{d}+\epsilon_{i, d}$ for each firm $i$ separately. $R_{i, d}$ denotes stock returns for firm $i$ at day $d$ and $M_{d}$ denotes returns from the Fama-French market factor. We use the time period between the beginning of 2012 and Friday, October 12, 2012 as the calibration period. Standard errors are independently clustered at the level of both firms and weeks (Cameron et al., 2011). ${ }^{9}$

Appendix Table A.3.1 presents the results. Returns and abnormal returns for REITs in the treatment group were indeed lower than those for REITs in the first control group as Hurricane Sandy approached New York City. All of the statistically significant coefficients for the week before Hurricane Sandy made landfall are negative for both returns and abnormal returns. Conversely, most of the statistically significant coefficients for the interaction terms after the week of uncertainty are positive. As relatively little damage to the buildings in the evacuation zone of New York City was

\footnotetext{
${ }^{9}$ This analysis differs from traditional return event studies. Instead of determining counterfactual outcomes in returns with the help of an asset pricing model, we use observed returns of REITs in the control group. Instead of testing whether abnormal returns determined as the difference between observed returns and returns predicted by an asset pricing model - are significantly different from zero, we test whether differences in returns between the treatment and the respective control groups are significantly different from zero. In this sense, conducting this analysis not only with returns but also with abnormal returns is only a way of further reducing residual variance to have greater statistical power, of course assuming that the asset pricing model is correctly specified.
} 


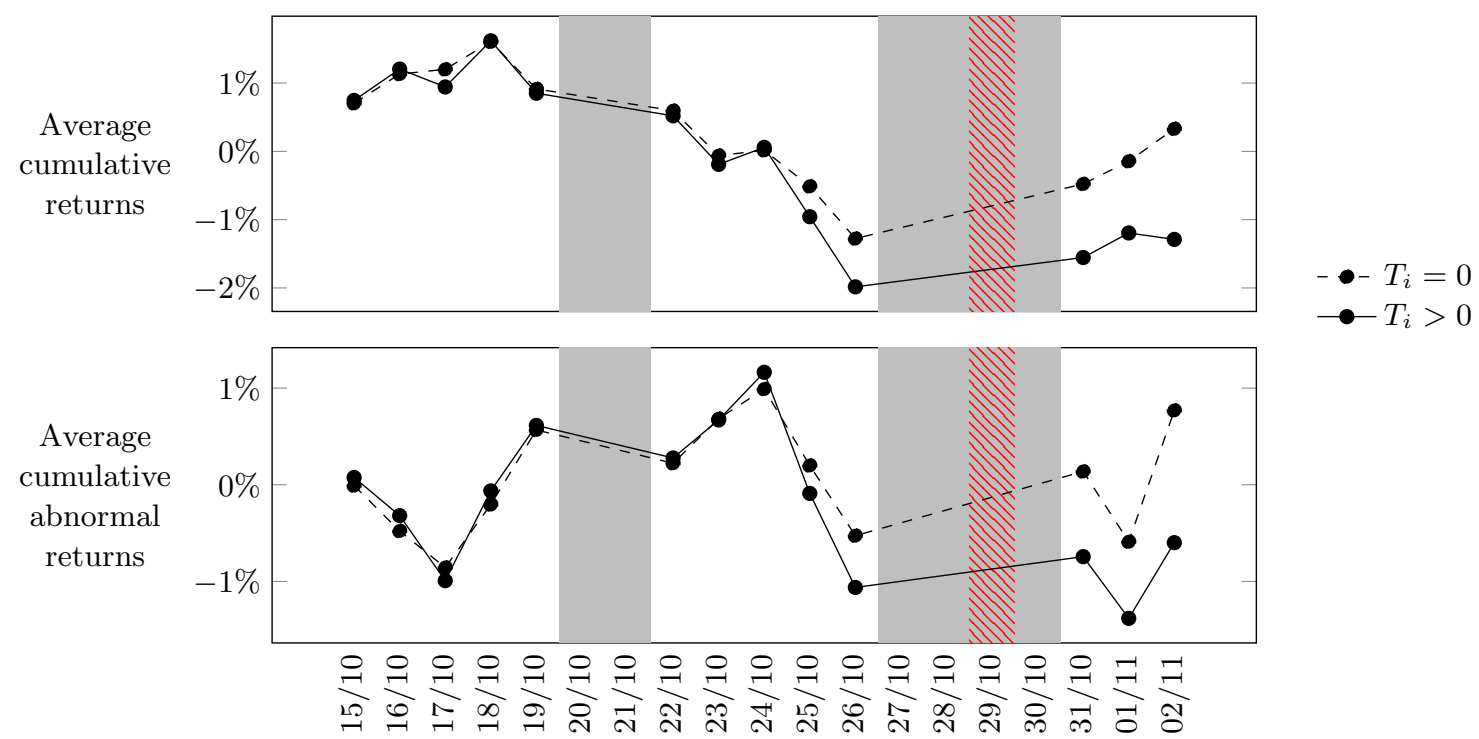

Figure 4: Cumulative returns

This figure presents average daily cumulative returns as well as average cumulative abnormal returns for the treatment group and the first control group in the two weeks prior to and one week after Hurricane Sandy's landfall. The treatment group consists of REITs holding property in the evacuation zone of New York City $\left(T_{i}>0\right)$. The first control group consists of REITs without property holdings in the evacuation zone of New York City $\left(T_{i}=0\right)$. Grey background marks indicate days on which the NYSE was closed, i.e. weekends as well as Monday, October 27 and Tuesday, October 28, 2012. Red-striped background marks indicate Monday, October 29, 2012 on which Hurricane Sandy made landfall. Abnormal returns are calculated as $A R_{i, d}=R_{i, d}-\beta_{i} M_{d}$, with $\beta_{i}$ being estimated in $R_{i, d}=\alpha_{i}+\beta_{i} M_{d}+\epsilon_{i, d}$ for each firm $i$ separately, $R_{i, d}$ denoting stock returns for firm $i$ at day $d, M_{d}$ denoting Fama-French market returns and using the time period between the beginning of 2012 and Friday, October 12, 2012 as the calibration period.

observed, investor concerns seem to have been alleviated and the return differentials did reverse to some extent.

\subsubsection{Risk}

The previous results for returns are encouraging in that investors seem to have been concerned about the impending storm and looming uncertainty. However, these results also raise the question whether returns decreased in line with an expected increase in the market price of risk. In turn, the effect of an risk increase on trading volume and bid-ask spreads could confound the identification of the effect of an increase in uncertainty.

Previous literature suggests that an increase in risk should widen spreads. Chung and Chuwonganant (2014) show empirically, that this relationship not only holds for firm-specific but also for systematic risk proxied by the VIX. This is in line with previous theoretical work such as Glosten and Milgrom (1985) and Ho and Stoll (1981). Therefore, a simultaneous increase in the market price of risk should lead to an overestimation of the effects of uncertainty on bid-ask spreads.

The theoretical work by Easley and O'Hara (2010) suggests that as the 
market price of risk increases, traders reduce the riskiness of their portfolios. This should lead to an increase in trading volume, offsetting the theorized trading volume diminishing effects of uncertainty. Hence, a simultaneously occurring increase in risk should lead to an underestimation of the effects of uncertainty on trading volume. If the net effect of the uncertainty shock and the potential risk shock on trading volume were to be negative, this could be interpreted as even stronger confirmation for the tested theoretical implication on trading volume.

We address the concerns about confounding variation in risk in two ways. First, we test statistically whether the week of uncertainty was accompanied by an increase intraday volatility as defined in subsection 3.2. ${ }^{10}$ Following our baseline specifications (1) and (2), we are only interested in the differences between the treatment and the control group in the week of uncertainty. Table 3 presents the results in the first two columns. We focus on the interaction terms between the indicator variables signifying the days in the week prior to and the week after the week of uncertainty as well as treatment intensity. None of the interaction terms $d_{w=43} \cdot T_{i}, d_{w>42} \cdot T_{i}$ and $d_{w>43} \cdot T_{i}$ is statistically significant, indicating that we cannot statistically detect a simultaneous increase in risk.

Second, we add the same measure of risk to our set of control variables in all regressions on trading volume and the different bid-ask spread measures. In doing so, the confounding effect of an increase in risk for the treated REITs relative to the respective control REITs should be accounted for.

\subsubsection{Information asymmetries}

Not only an increase in risk but also an increase in information asymmetries between investors of REITs in the treatment group relative to REITs in the two control groups could have led to variation confounding the identification of the effect of uncertainty on trading volume and bid-ask spreads. As Hurricane Sandy approached New York City, some investors might have been either better equipped than others to process information available on the exact location of REIT properties, the insurance status of these properties etc. or might even have been able to generate more direct private information on REITs holding property in the evacuation zone. The extant literature, such as Glosten and Milgrom (1985), suggests that an increase of information asymmetries between market participants should lower trading volume and should increase bid-ask spreads.

While the generation of private information is generally difficult to observe, some factors might have mitigate this concern. First, the location of the individual properties is generally readily available to market participants through the website and reports of a given REIT or through financial market information services such as SNL, that we also used to compile our dataset that contains geo-coordinates for each property. In any case, dif-

\footnotetext{
${ }^{10}$ Unfortunately, more forward-looking measures of risk such as implied volatility from options trading are largely unavailable for REITs.
} 
Table 3: Regression results for intraday volatility and price impact

This table presents difference-in-differences estimates comparing dollar volume or price impact of a treatment group and the first control group in the week prior to Hurricane Sandy's landfall, i.e. the week of uncertainty. The treatment group consists of REITs holding property in the evacuation zone of New York City. The first control group consists of REITs without property holdings in the evacuation zone of New York City. Specifications (1) and (3) are of the form: $\log \left(y_{i, w}\right)=\beta_{0} d_{w=43}+\beta_{1}\left(d_{w=43} \cdot T_{i}\right)+D_{i=j} \Gamma+D_{w=u} \Delta+\epsilon_{i, w}$. Specifications (2) and (4) are of the form: $\log \left(y_{i, w}\right)=\beta_{0} d_{w>42}+\beta_{1} d_{w>43}+\beta_{2}\left(d_{w>42}\right.$. $\left.T_{i}\right)+\beta_{3}\left(d_{w>43} \cdot T_{i}\right)+D_{i=j} \Gamma+D_{w=u} \Delta+\epsilon_{i, w} \cdot i$ and $w$ index firms and weeks. The dataset contains weekly observations until the fifth week after the week of uncertainty $(w=43)$, i.e. $w \in[1,48] . \quad y_{i, w}$ denotes either intraday volatility or price impact. $d_{w}$ and $d_{i}$ are indicator variables identifying firms and weeks. $D_{i}$ and $D_{w}$ denote firm and time fixed effects, i.e. matrices of $d_{j}$ 's and $d_{u}$ 's using the first firm's identifier and the first week as base category $(j>1$ and $u>1)$ and not containing the week prior to Hurricane Sandy's landfall $(u \neq 43)$. For brevity, firm and time fixed effects are omitted in this table. $T_{i}$ denotes the treatment intensity defined as the percentage share of the book value invested in the evacuation zone of New York City, with $T_{i}>0$ for the treatment group and $T_{i}=0$ for both control groups. The treatment intensity $T_{i}$ is not separately included in the specifications since it is time-fixed and is already captured by the firm-fixed effects $D_{i}$. $X_{i, w}$ denotes control variables, in this case intraday volatility and price impact. Standard errors are independently clustered at the level of both firms and weeks (Cameron et al., 2011). $t$-statistics are shown in parentheses, $p$-values are denoted as ${ }^{*}$ for $p<0.05,{ }^{* *}$ for $p<0.01$ and $^{* * *}$ for $p<0.001$.

\begin{tabular}{|c|c|c|c|c|}
\hline \multirow{2}{*}{$\begin{array}{l}\text { Dependent variable } \\
\text { Specification }\end{array}$} & \multicolumn{2}{|c|}{$\log \left(\right.$ Intraday volatility $\left._{i, w}\right)$} & \multicolumn{2}{|c|}{ Price impact $_{i, w}$} \\
\hline & (1) & (2) & (3) & (4) \\
\hline \multicolumn{5}{|l|}{ Independent variables } \\
\hline$d_{w=43}$ & $\begin{array}{l}-0.309^{* * *} \\
(-4.72)\end{array}$ & & $\begin{array}{l}-0.013^{* * *} \\
(-4.11)\end{array}$ & \\
\hline$d_{w>42}$ & & $\begin{array}{l}-0.303^{* * *} \\
(-5.16)\end{array}$ & & $\begin{array}{l}-0.012^{* *} \\
(-3.92)\end{array}$ \\
\hline$d_{w>43}$ & & $\begin{array}{c}0.734^{* * *} \\
(10.67)\end{array}$ & & $\begin{array}{l}0.009^{*} \\
(2.11)\end{array}$ \\
\hline$d_{w=43} \cdot T_{i}$ & $\begin{array}{c}0.993 \\
(1.46)\end{array}$ & & $\begin{array}{c}0.035 \\
(1.72)\end{array}$ & \\
\hline$d_{w>42} \cdot T_{i}$ & & $\begin{array}{c}0.458 \\
(0.49)\end{array}$ & & $\begin{array}{l}-0.002 \\
(-0.03)\end{array}$ \\
\hline$d_{w>43} \cdot T_{i}$ & & $\begin{array}{r}-5.483 \\
(-1.38) \\
\end{array}$ & & $\begin{array}{l}-0.346 \\
(-1.74) \\
\end{array}$ \\
\hline Observations & 3696 & 3696 & 3696 & 3696 \\
\hline Adjusted $R^{2}$ & 0.65 & 0.65 & 0.79 & 0.79 \\
\hline
\end{tabular}


ferences in the availability of information would have to be correlated with the treatment status in order to confound our analysis. Second, New York City is arguably the best-known property investment area in the world, with investors from all over the world being likely able to distinguish between waterfront and non-waterfront properties, Upper and Lower Manhattan etc. Third, the geographic location of the affected properties close to the NYSE and many financial market participants will likely have made it quite difficult to generate private information. Market participants could easily observe in person, whether properties were properly secured and prepared for impending flooding etc.

We address any remaining concerns regarding the confounding effects of information asymmetry in two ways. In line with the way we address concerns about risk, we first test statistically whether the week of uncertainty was accompanied by an increase in information asymmetries, approximated by price impact as defined in subsection 3.2. We again follow our baseline specifications (1) and (2). Table 3 presents the results in columns 3 and 4 . We focus on the interaction terms between the indicator variables signifying the days in the week prior to and the week after the week of uncertainty as well as treatment intensity. None of the interaction terms is statistically significant, indicating that we cannot statistically detect a simultaneous increase in information asymmetry.

Second, we also add our measure of information asymmetry to our set of control variables in all regressions that follow. Any confounding effect of an simultaneous increase in information asymmetry for the treated stocks relative to the control stocks should thereby be accounted for.

\section{Results}

Table 4 presents the results of estimating model specifications (1) and (2) for all four dependent variables. Panel I shows the results for the first control group and Panel II for the second control group. We focus on the coefficients of the interaction terms between the indicator variables signifying the week of uncertainty and the treatment intensity, i.e. $d_{w=43} \cdot T_{i}$ or $d_{w>42} \cdot T_{i}$ and $d_{w>43} \cdot T_{i}$. Since the dependent variables are log-transformed, the regression coefficients of the respective interaction terms indicate the percentage difference in stock liquidity between the treatment group and the control group. According to the theory presented in section 2, the coefficient should be negative for dollar volume and positive for the different spread measures.

First control group Columns 1 and 2 show the effects of the uncertainty shock in week $w=43$ on the dollar volume using the first control group, which consists of all REITs without property holding in the evacuation zone of New York City for both model specifications. The results indicate a statistically significant and economically large effect. The point estimate of -2.126 in column 1 implies that during the week of uncertainty, a REIT with a treatment intensity of 10 percent had a 21 percent lower trading volume. 
With an average treatment intensity of 4 percent for the treatment group, this relates to an ATT of about 8.5 percent. In column 2, we decompose this effect into an initial treatment effect and a treatment reversal effect. The point estimates for both effects are statistically significant and amount to -2.068 and 2.632. This indicates that the dollar volume for the treatment group dropped considerably in the week of uncertainty and increased again in the following week, when Hurricane Sandy had passed New York City. Columns 3 and 4 show similar results for the effect of uncertainty on the closing spread. The point estimate of 1.738 in column 3 implies that the ATT was about 7 percent. Column 4 illustrates that the closing spread also shows a similar increase and reversal pattern as the dollar volume. Columns 5 to 8 present the results for quoted spread and effective spread. Estimating specification (1) yields statistically significant point estimates of 0.509 in column 5 for quoted spread and of 0.468 in column 7 for effective spread, which convert into ATTs of about 2 percent and of about 1.9 percent. This is considerably lower than for closing spread. Estimating model specification (2) for quoted spread and effective spread only partially yields coefficients that are significantly different from zero.

Second control group Using the second control group, which consists of all REITs that do not have any properties in the states of New Jersey and New York, the results for dollar volume and closing spread are magnified. The magnification becomes apparent, for instance, when comparing the point estimates for the interaction term in column 1 of Panel I and column 1 of Panel II, in which dollar volume is the dependent variable and model specification (1) is used. While the point estimate is -2.126 for the first control group, it is -3.062 for the second control group. These point estimates relate to ATTs of 8.5 percent and 12 percent respectively. The larger treatment effect for the second control group relative to the first control group makes intuitive sense. While the first control group is likely to be also partially affected by the uncertainty shock since it also includes REITs with properties in any affected areas outside New York City (e.g. properties in Jersey City), the second control group is less likely to be affected by the uncertainty shock since it puts more geographic restrictions on the selection of the control firms. This observation also holds for closing spread, but the results for quoted spread and effective spread further weaken when using the second control group, both in terms of statistical and economic significance.

Overall, the results indicate a statistically and economically significant impact of uncertainty on dollar volume and bid-ask spreads. This supports the negative impact of uncertainty on market liquidity hypothesized by Easley and O'Hara (2010), Ozsoylev and Werner (2011) and Routledge and Zin (2009). However, the results for closing spread are stronger than for intraday spreads. This may be the case, because intraday spreads capture more of the intraday demand and supply dynamics of securities unrelated to long-term information rather than the uncertainty concerns of longer term investors. Given that a considerable proportion of trading happens at closing 
auction prices and that institutional traders participate more in the closing auction than intraday trading, it makes sense to assign closing spreads a higher weight than intraday spreads. Nevertheless, all of our spread results point in the same direction.

\section{Robustness checks}

The test the robustness of the results presented in the previous section withstand by focussing on two of the key identifying assumptions: The selection of the pre-treatment time window and the sufficiency of the firm fixed effects as well as intraday volatility and price impact to account for firm-specific determinants of stock liquidity.

Shorter pre-treatment time window As argued previously in subsection 3.4, the length of the pre-treatment time window determines the reference observations relative to which a change in stock liquidity is measured. Our initial choice of a sample that starts at the beginning of 2012 was guided by the consistency with the definition of the treatment intensity variable, for which data is only available for the end of 2011. In Appendix Table A.4.1 we present results when the sample is further limited to the 20 weeks prior to the week of uncertainty. Panels and column numbers correspond to the panels and column numbers presented in Table 4: Panel I present results for the first control group, Panel II shows results for the second control group. For dollar volume and closing spread, most coefficients for the interaction term between the uncertainty week indicators and the treatment intensity remain statistically significant. However, the size of the coefficient changes slightly. When using dollar volume as the dependent variable, the effect size is slightly reduced; when using closing spread as the dependent variable, the effect size is slightly increased. This applies both to the use of the first as well as the second control group. For the dollar volume specification in column 1 of Panel I, the ATT is reduced from about 8.5 percent to about 6.6 percent. For the closing spread specification in column 3 of Panel I, the ATT is increased from about 7 percent to about 9.7 percent. However, the main difference between using either of the control groups remains the same. The effect size is larger for the second control group. The results for quoted spread and effective spread are weaker again, with hardly any coefficient of the interaction terms being statistically different from zero.

Full covariate adjustment In our baseline specifications, we solely use firm fixed effects as well as intraday volatility and price impact for holding firm-specific determinants of stock liquidity constant. In Appendix Table A.4.4 we add a full set of alternative, time-varying control variables, mostly firm fundamentals. These variables are further defined in Appendix subsection A.1. However, the size of the observed treatment effects do not change much by the inclusion of these additional explanatory variables and 


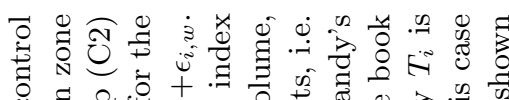

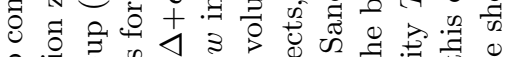

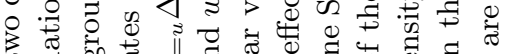
है 菏

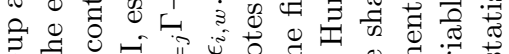

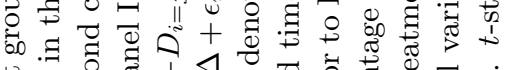

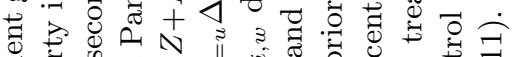

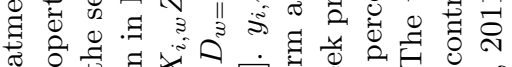

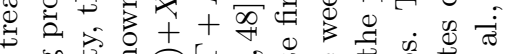

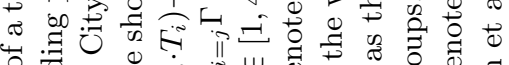

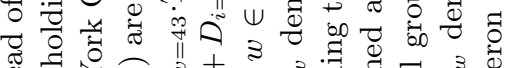

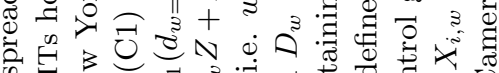
国

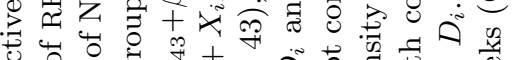

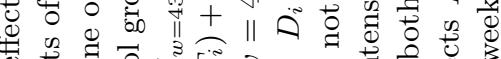

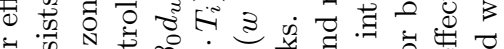
o 范

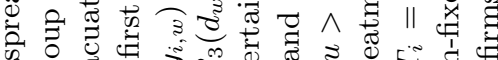

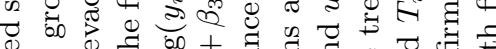

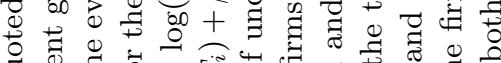

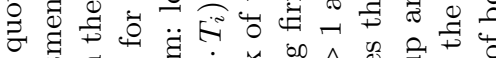

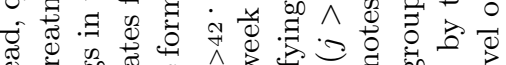

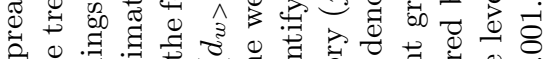
की oo

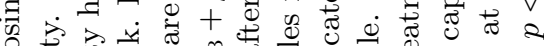

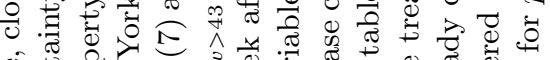

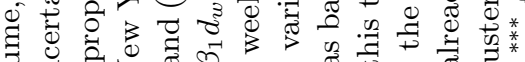

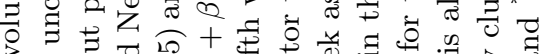

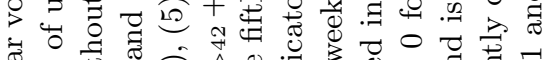

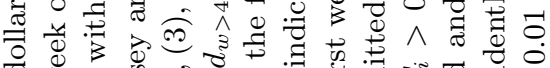

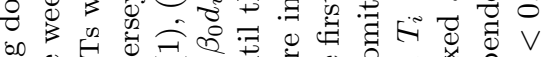

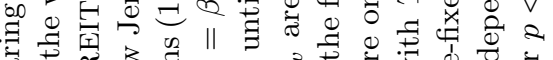

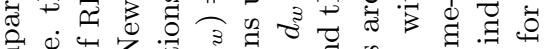
영.-

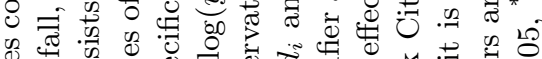

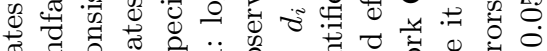

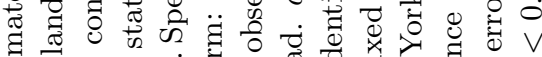
诸 ष

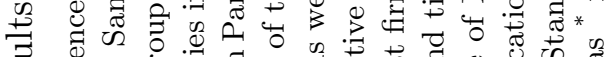

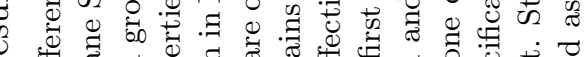

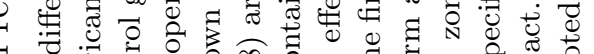

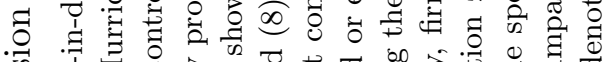

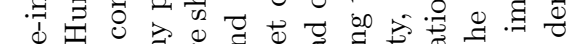

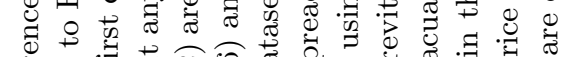

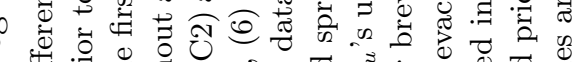

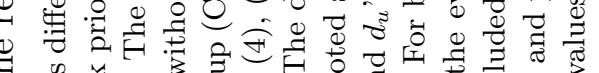

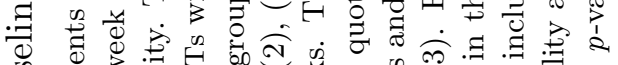
の

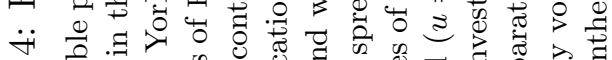

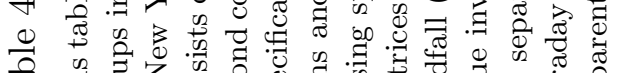

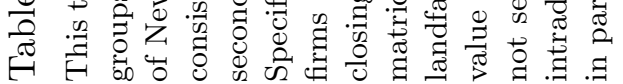

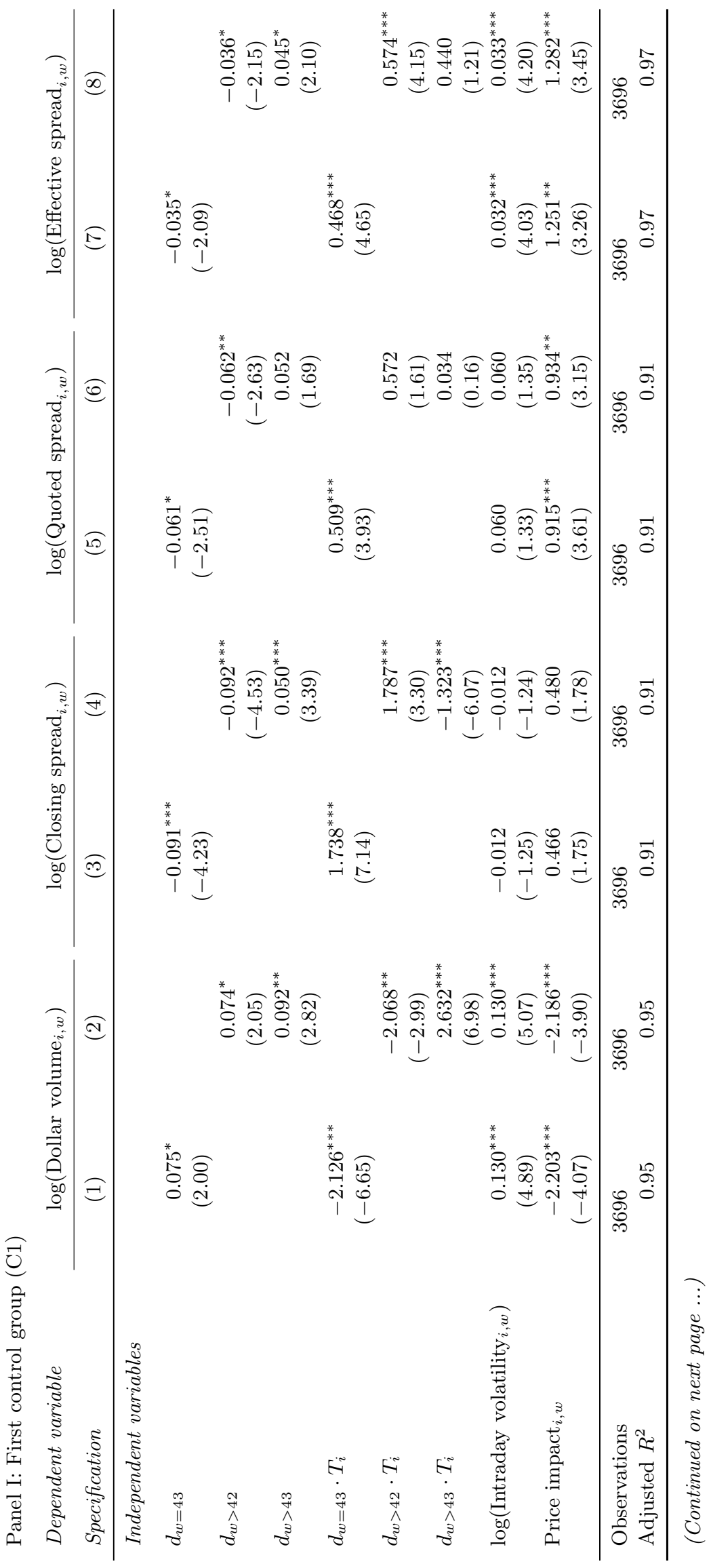




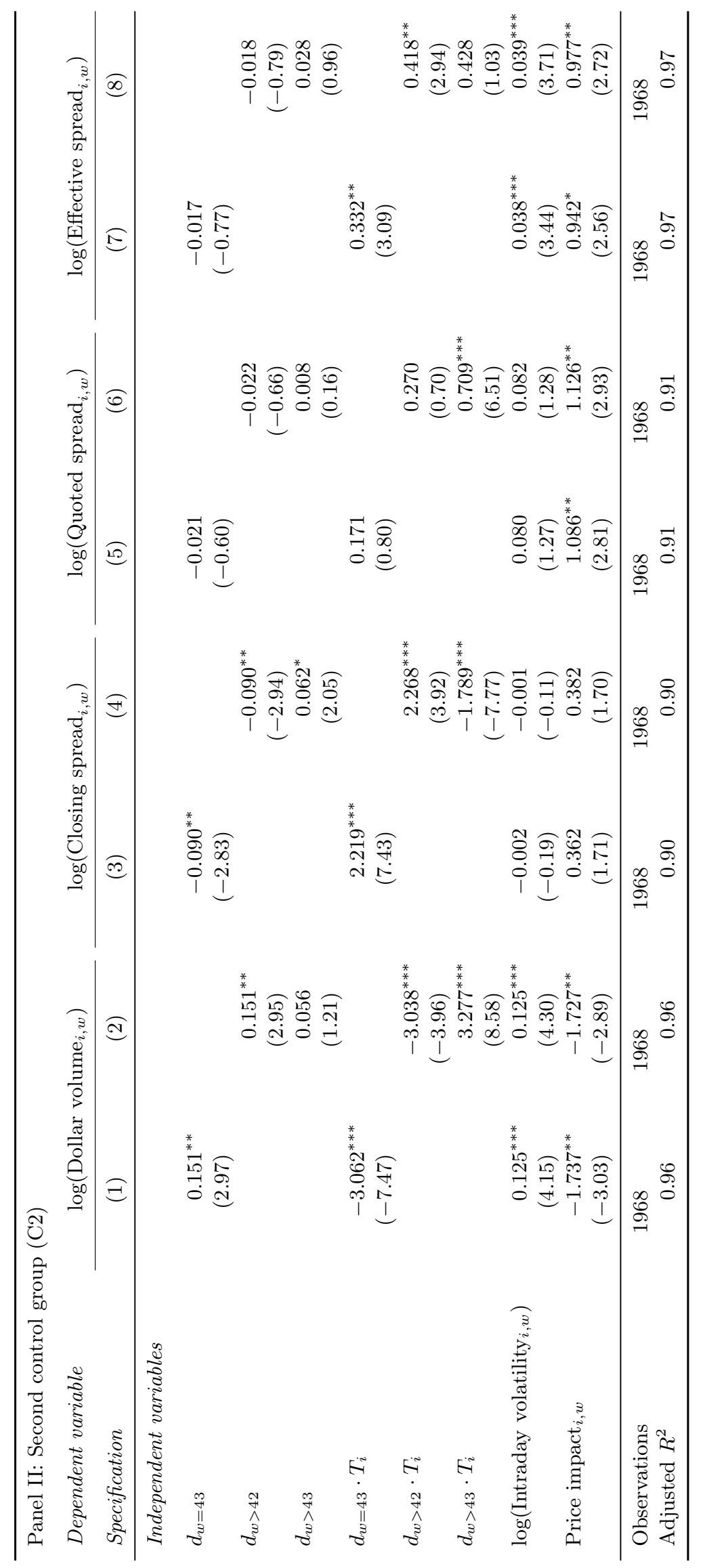


the effect size differences between the first and the second control group remain almost the same as well. This result is in line with the observation, that REITs in the treatment and control groups differ only along very few dimensions other than in their property portfolio. Table 2 presents differencein-mean $t$-tests for all covariates in the week prior to the treatment. Except for the leverage ratio and firm size, no statistically significant differences can be observed. Even if such differences would be observed, however, they would also have to systematically bias the effect of the uncertainty shock on the treatment and control groups in order to invalidate the differencein-differences approach used for identification. For instance, higher levered firms would have to react systematically different to the uncertainty shock. Assuming that the selection of the added covariates is sufficiently complete and valid, this seems not to be the case.

Lasso-based covariate adjustment To dispel any concerns about the selection of the added covariates from the pool of possible covariates, we also provide results where covariates are not selected subjectively but algorithmically. Belloni et al. (2014a) suggest to use a "post-double-selection" procedure based on the least absolute shrinkage and selection operator (Lasso) employed widely in the machine learning literature in order to conduct automatic variable selection. The underlying assumption is that a rather small set of explanatory variables is responsible for explaining most of the variation in the dependent variable. ${ }^{11}$ This sparsity assumption is parameterized as $\lambda$. Belloni et al. (2014a) suggest to use the heuristic introduced by Bickel et al. (2009) to determine $\lambda$. We follow their suggestions and apply the postdouble-selection method with this heuristic to our dataset in order to select the relevant covariates. The results are shown in Appendix Table A.4.6. Our conclusions remain largely unchanged.

\section{Conclusion}

In this paper we provide an empirical test of recent theoretical work on the effects of uncertainty on market liquidity. We use the week prior to Hurricane Sandy's landfall in October 2012 as a natural experiment, which provided an environment of great uncertainty for stocks of REITs with property invested in the evacuation zone of New York City. Due to the unprecedented strength, scale and nature of the Hurricane, the potential consequences of the storm were nearly impossible to quantify. We argue that the observed uncertainty shock was an uncertainty shock in the sense of Knight (1921), rather than purely a period of increased risk. For identification we use a differencein-differences framework and compare the trading volume and the bid-ask spread of stocks of REITs with and without property invested in the affected area. The results for trading volume are both statistically and economically significant and confirm the theoretical implications. The results for bid-ask

\footnotetext{
${ }^{11}$ Belloni et al. (2014b) provide a more formalized but yet intuitive introduction to this stream of the literature.
} 
spread generally show statistically significant coefficients in the direction predicted by theory. We interpret this as tentative empirical evidence on the effects of uncertainty on market liquidity. Together these results suggest a decrease in welfare as fewer gains from trade are realized. This provides some evidence on the potential magnitude of the effects of uncertainty on markets.

We see various avenues for further research on the effects of uncertainty on market liquidity and market microstructure in general. On a theoretical level, the effects of uncertainty on liquidity have only started to enter the literature. To our knowledge, the models of Easley and O'Hara (2010), Ozsoylev and Werner (2011) and Routledge and Zin (2009) are the only theoretical models that explicitly address uncertainty in the understanding of Knight (1921) so far. In this regard the theoretical literature on market liquidity is lacking behind the fast developing stream of literature on the effects of uncertainty in the macroeconomic and macro-finance context. ${ }^{12}$ One aspect worth exploring might be to model the effects of uncertainty on other dimensions of market liquidity such as price impact.

At the methodological level, the quasi-experimental empirical test provided in this paper is only one of many possible ways of testing the theory of the effects of uncertainty on market liquidity. While quasi-experimental setups can provide valid tests of theoretical predictions, they are usually scarce, do not occur repeatedly and therefore cannot be easily replicated. Laboratory experiments might be an attractive avenue to address these concerns. For instance, artificial security markets in the spirit of the experiments described in Smith (1962) might be a well-suited complement to evidence collected in the field.

\footnotetext{
${ }^{12}$ See Bloom et al. (forthcoming) for a recent and highly visible example in the macroeconomic context and Segal et al. (2015) for a recent example in the macro-finance context.
} 


\section{References}

Belloni, Alexandre, Victor Chernozhukov, and Christian Hansen, 2014a, Inference on Treatment Effects after Selection among High-Dimensional Controls, Review of Economic Studies 81, 608-650.

Belloni, Alexandre, Victor Chernozhukov, and Christian Hansen, 2014b, Inference on Treatment Effects after Selection among High-Dimensional Controls, Journal of Economic Perspectives 28, 29-50.

Bernile, Gennaro, George Korniotis, Alok Kumar, and Qin Wang, 2015, Local Business Cycles and Local Liquidity, Journal of Financial and Quantitative Analysis 50, 987-1010.

Bertrand, Marianne, Esther Duflo, and Sendhil Mullainathan, 2004, How Much Should We Trust Differences-In-Differences Estimates?, Quarterly Journal of Economics 119, 249-275.

Bewley, Truman F., 2002, Knightian decision theory. Part I, Decisions in Economics and Finance 25, 79-110.

Bharath, Sreedhar T., and Tyler Shumway, 2008, Forecasting Default with the Merton Distance to Default Model, Review of Financial Studies 21, 1339-1369.

Bickel, Peter J., Ya'acov Ritov, and Alexandre B. Tsybakov, 2009, Simultaneous analysis of Lasso and Dantzig selector, Annals of Statistics 37, $1705-1732$

Bloom, Nicholas, 2014, Fluctuations in Uncertainty, Journal of Economic Perspectives 28, 153-176.

Bloom, Nicolas, Max Floetotto, Nir Jaimovich, Itay Saporta, and Stephen Terry, forthcoming, Really Uncertain Business Cycles, Econometrica .

Brandon, Christine M., Jonathan D. Woodruff, Jeffrey P. Donnelly, and Richard M. Sullivan, 2014, How Unique was Hurricane Sandy? Sedimentary Reconstructions of Extreme Flooding from New York Harbour, Scientific Reports 4.

Brunnermeier, Markus K., 2009, Deciphering the Liquidity and Credit Crunch 2007-2008, Journal of Economic Perspectives 23, 77-100.

Cameron, A. Colin, Jonah B. Gelbach, and Douglas L. Miller, 2011, Robust Inference With Multiway Clustering, Journal of Business $\&$ Economic Statistics 29, 238-249.

Chung, Kee H., and Chairat Chuwonganant, 2014, Uncertainty, market structure, and liquidity, Journal of Financial Economics 113, 476-499.

Chung, Kee H., and Hao Zhang, 2014, A simple approximation of intraday spreads using daily data, Journal of Financial Markets 17, 94-120. 
Easley, David, and Maureen O'Hara, 2010, Liquidity and valuation in an uncertain world, Journal of Financial Economics 97, 1-11.

Glosten, Lawrence R., and Paul R. Milgrom, 1985, Bid, ask and transaction prices in a specialist market with heterogeneously informed traders, Journal of Financial Economics 14, 71-100.

Ho, Thomas, and Hans R. Stoll, 1981, Optimal dealer pricing under transactions and return uncertainty, Journal of Financial Economics 9, 47-73.

Holden, Craig W., and Stacey Jacobsen, 2014, Liquidity Measurement Problems in Fast, Competitive Markets: Expensive and Cheap Solutions, Journal of Finance 69, 1747-1785.

Karolyi, G. Andrew, Kuan-Hui Lee, and Mathijs A. van Dijk, 2012, Understanding commonality in liquidity around the world, Journal of Financial Economics 105.

Knight, Frank H., 1921, Risk, Uncertainty, and Profit, first edition (Houghton Mifflin Co. and The Riverside Press, Boston and New York, USA).

Ozsoylev, Han, and Jan Werner, 2011, Liquidity and asset prices in rational expectations equilibrium with ambiguous information, Economic Theory $48,469-491$.

Routledge, Bryan R., and Stanley E. Zin, 2009, Model uncertainty and liquidity, Review of Economic Dynamics 12, 543-566.

Segal, Gill, Ivan Shaliastovich, and Amir Yaron, 2015, Good and bad uncertainty: Macroeconomic and financial market implications, Journal of Financial Economics 117, 369-397.

Smith, Vernon L., 1962, An Experimental Study of Competitive Market Behavior, Journal of Political Economy 70, 369-397.

Vayanos, Dimitri, and Jiang Wang, 2013, Market Liquidity - Theory and Empirical Evidence, in George Constantinides, Milton Harris, and Rene Stulz, eds., Handbook of the Economics of Finance, volume 2, part B, chapter 19, 1289-1361. 


\section{A Appendix}

\section{A.1 Variable definitions}

$q$ denotes end of quarter,

$w$ denotes end of a week in this quarter,

$d$ denotes end of a trading day in this week,

$t$ denotes points of time during this trading day (i.e. intraday data).

Dollar volume $_{i, d}=$ No. of shares traded vi,d $\times$ Closing price $_{i, d}$

Dollar volume $_{i, w}=$ Mean $\left(\right.$ Dollar volume $\left._{i, d}\right)$ for all $d$ in a given week $w$

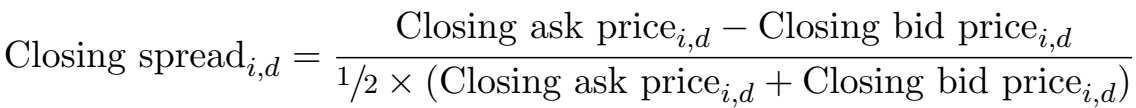

Closing $\operatorname{spread}_{i, w}=\operatorname{Mean}\left(\operatorname{Closing}_{\operatorname{spread}}{ }_{i, d}\right)$ for all $d$ in a given week $w$

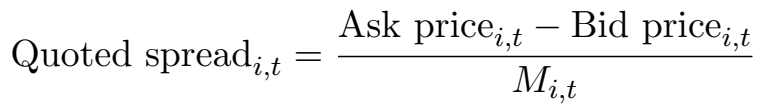

with midpoint price $M_{i, t}=1 / 2 \times\left(\right.$ Ask price $\left._{i, t}+{\left.\text { Bid } \text { price }_{i, t}\right)}\right)$

Quoted $\operatorname{spread}_{i, d}=$ Mean $\left(\right.$ Quoted $\left.\operatorname{spread}_{i, t}\right)$ for all $t$ in a given trading day $d$

\left.${\text { Quoted } \operatorname{spread}_{i, w}=\operatorname{Mean}(\text { Quoted } \operatorname{spread}}_{i, d}\right)$ for all $d$ in a given week $w$

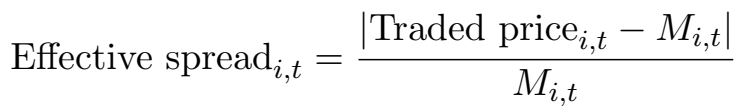

with midpoint price $M_{i, t}=1 / 2 \times\left(\right.$ Ask price $\left._{i, t}+{\left.\text { Bid } \text { price }_{i, t}\right)}\right)$

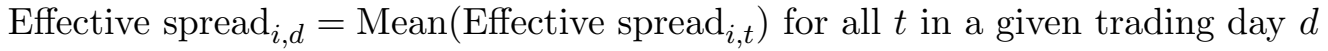

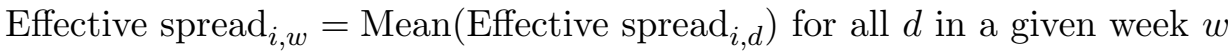

Intraday volatility $_{i, d}=\sqrt{\frac{1}{N-1} \sum_{t=\text { open }}^{\text {close }}\left(R_{i, t}-\bar{R}\right)^{2}}$

with $R_{i, t}$ denoting 5-minute returns of the respective midpoint price $M_{i, t}$

Intraday volatility $_{i, w}=$ Mean(Intraday volatility ${ }_{i, d}$ ) for all $d$ in a given week $w$

Price impact $_{i, t}=D_{i, t} \frac{M_{i, t+5 m i n}-M_{i, t}}{M_{i, t}}$

with $D_{i, t}$ being +1 for buyer initiated trades and -1 for

seller initiated trades

Price impact $_{i, d}=$ Mean $\left(\right.$ Price impact $\left._{i, t}\right)$ for all $t$ in a given trading day $d$

Price impact $_{i, w}=$ Mean(Price impact $_{i, d}$ ) for all $d$ in a given week $w$ 
Debt-to-assets $_{i, q}=\frac{\text { Total debt }_{i, q}}{{\text { Total } \operatorname{assets}_{i, q}}}$

Debt-to-assets $_{i, w}=$ Debt-to-assets $_{i, q}$ for all $w$ in quarter $q$

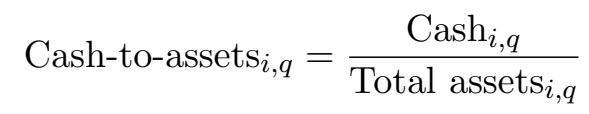

Cash-to-assets ${ }_{i, w}=$ Cash-to-assets $_{i, q}$ for all $w$ in quarter $q$

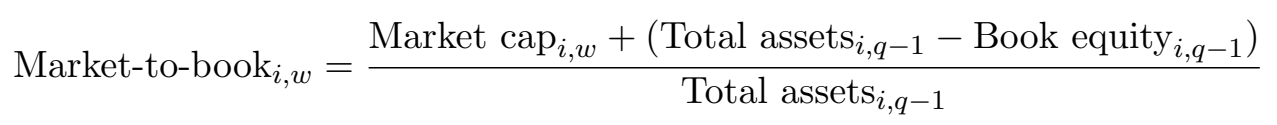

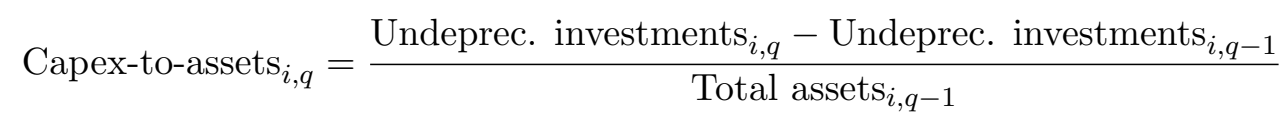

Capex-to-assets $_{i, w}=$ Capex-to-assets $_{i, q}$ for all $w$ in quarter $q$

Probability of default ${ }_{i, w}=$ As defined by Bharath and Shumway (2008) with one year rolling window

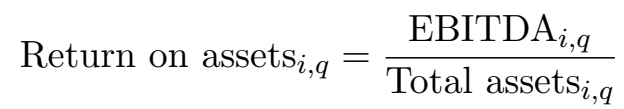

Return on $\operatorname{assets}_{i, w}=$ Return on $\operatorname{assets}_{i, q}$ for all $w$ in quarter $q$ 


\section{A.2 REIT properties in Manhattan}

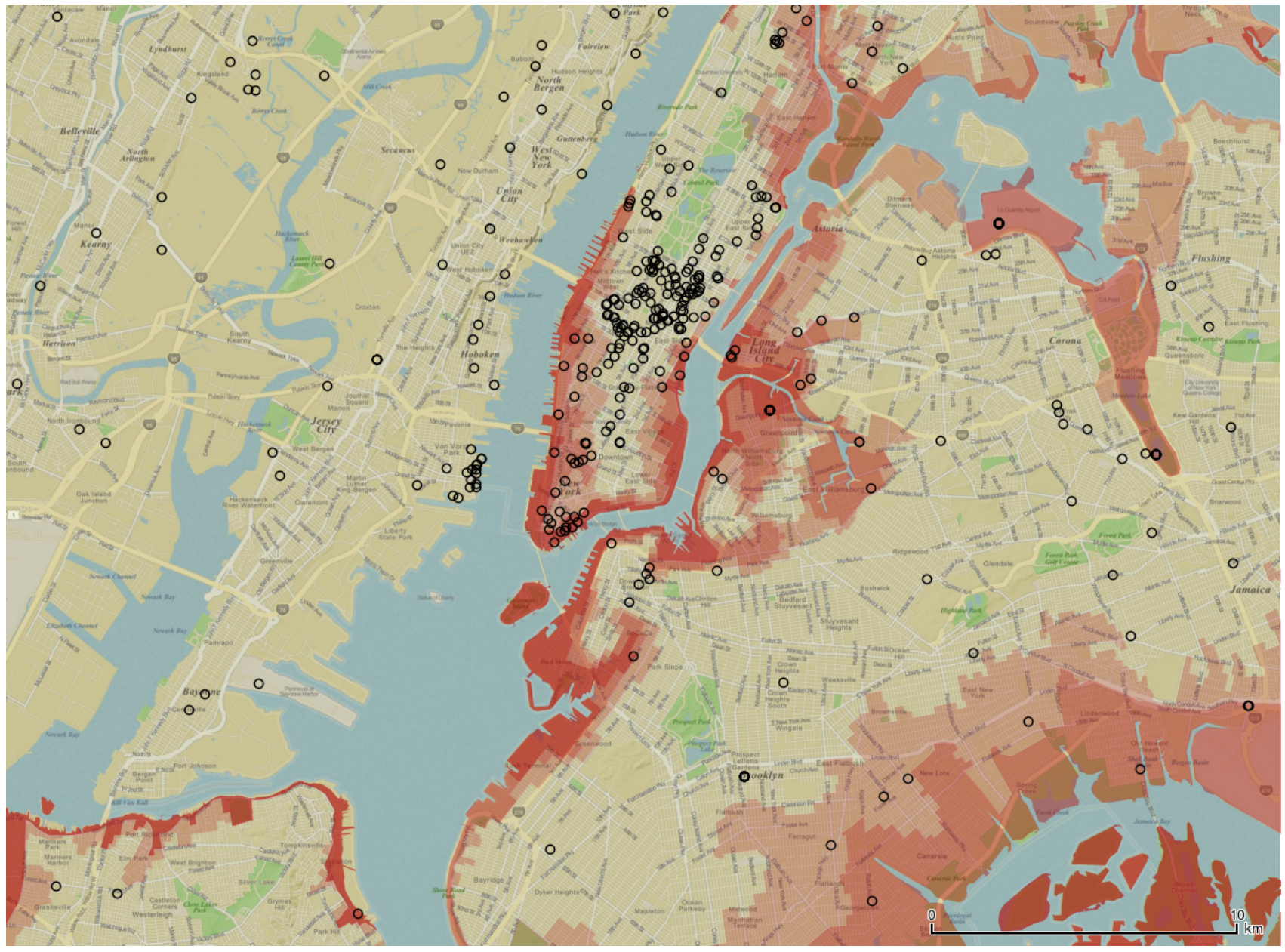

Figure A.2.1: REIT properties in Manhattan

Individual properties are shown as black circles. The sub-evacuation zones are colored in red: Zone $\mathrm{A}$ in dark red, zone $\mathrm{B}$ in medium red, zone $\mathrm{C}$ in light red. 


\section{A.3 Regression results for returns}

Table A.3.1: Regression results for returns

This table presents estimates comparing daily returns $\left(R_{i, d}\right)$ and abnormal returns $\left(A R_{i, d}\right)$ between the treatment group and the first control group in the two weeks prior to and one week after Hurricane Sandy's landfall. The treatment group consists of REITs holding property in the evacuation zone of New York City $\left(T_{i}>0\right)$. The first control group consists of REITs without property holdings in the evacuation zone $\left(T_{i}=0\right)$. The dataset contains daily observations between Monday, October 01 and Friday, November 02, 2012. The specification is of the form: $y_{i, d}=\beta_{0}+\beta_{1}\left(d_{d=\text { Oct. } 22} \cdot T_{i}\right)+\beta_{1}\left(d_{d=\text { Oct.23 }}+\ldots+\right.$ $\beta_{8}\left(d_{d=\text { Nov.02 }} \cdot T_{i}\right)+\epsilon_{i, d}$, with $y_{i, d}$ denoting either $R_{i, d}$ or $A R_{i, d}$. The interaction terms $d_{d} \cdot T_{i}$ consist of trading day indicator variables $d_{d}$ and treatment intensity $T_{i}$, defined as the percentage share of the book value invested in the evacuation zone of New York City. The coefficients $\beta_{1}$ to $\beta_{8}$ indicate average differences in returns or abnormal returns relative to the baseline period between Monday, October 01 and Friday, October 19, 2012. The red line indicates Hurriance Sandy's landfall on October 29, 2012. Abnormal returns are calculated as $A R_{i, d}=R_{i, d}-\beta_{i} M_{d}$, with $\beta_{i}$ being estimated in $R_{i, d}=\alpha_{i}+\beta_{i} M_{d}+\epsilon_{i, d}$ for each firm $i$ separately, $R_{i, d}$ denoting stock returns for firm $i$ at day $d, M_{d}$ denoting Fama-French market returns and using the time period between the beginning of 2012 and Friday, October 12, 2012 as the calibration period. Standard errors are independently clustered at the level of both firms and weeks (Cameron et al., 2011). $t$-statistics are shown in parentheses, $p$-values are denoted as ${ }^{*}$ for $p<0.05,{ }^{* *}$ for $p<0.01$ and ${ }^{* * *}$ for $p<0.001$.

\begin{tabular}{lcc}
\hline Dependent variable & Returns $\left(R_{i, d}\right)$ & Abnormal returns $\left(A R_{i, d}\right)$ \\
\hline Independent variables & & \\
$d_{d=\text { Oct. } 22} \cdot T_{i}$ & 0.007 & 0.002 \\
& $(0.12)$ & $(0.03)$ \\
$d_{d=\text { Oct. } 23} \cdot T_{i}$ & $-0.106^{* * *}$ & 0.014 \\
& $(-3.77)$ & $(0.62)$ \\
$d_{d=\text { Oct. } 24} \cdot T_{i}$ & 0.082 & 0.105 \\
& $(1.47)$ & $(1.84)$ \\
$d_{d=\text { Oct. } 25} \cdot T_{i}$ & $-0.132^{* *}$ & $-0.162^{* * *}$ \\
& $(-2.86)$ & $(-3.47)$ \\
$d_{d=\text { Oct.26 }} \cdot T_{i}$ & $-0.112^{* *}$ & $-0.109^{* *}$ \\
& $(-2.89)$ & $(-2.63)$ \\
\hline$d_{d=\text { Oct.31 }} \cdot T_{i}$ & $0.051^{* * *}$ & 0.034 \\
$d_{d=\text { Nov.01 }} \cdot T_{i}$ & $(3.58)$ & $(1.61)$ \\
$d_{d=\text { Nov. } 02} \cdot T_{i}$ & $0.049^{*}$ & $-0.068^{*}$ \\
& $(2.11)$ & $(-2.24)$ \\
\hline Observations & 0.023 & $0.118^{* * *}$ \\
Adjusted $R^{2}$ & $(0.61)$ & $(3.72)$ \\
\hline
\end{tabular}

\section{A.4 Regression results for robustness checks}

- See following pages - 


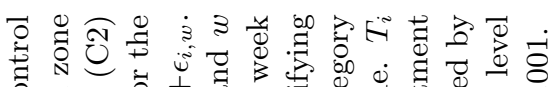

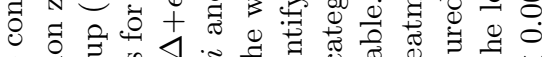

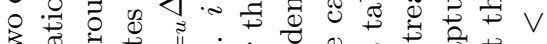

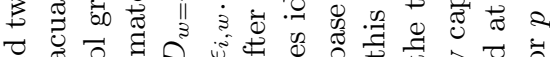

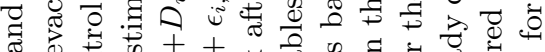

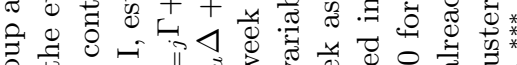

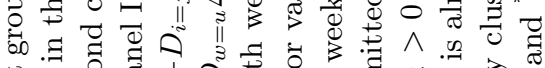

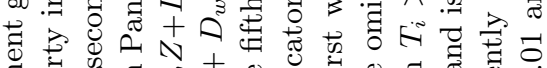

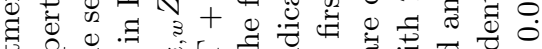

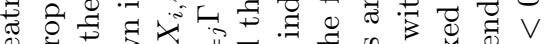

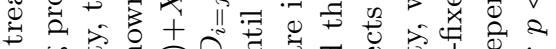
๘ 응

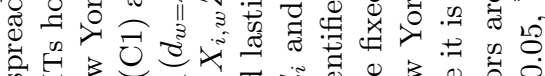
की

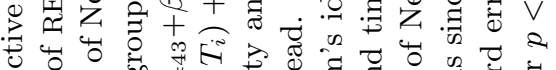

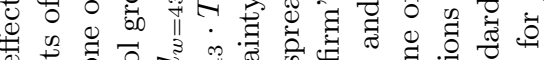

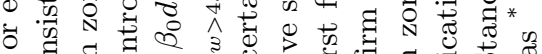
范

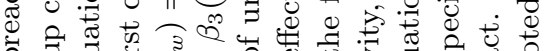
के

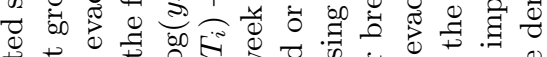

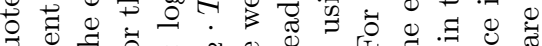

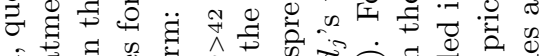

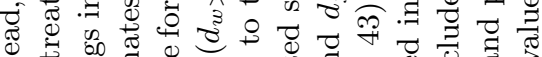

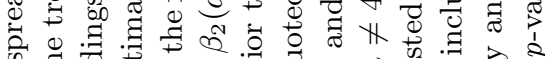
की

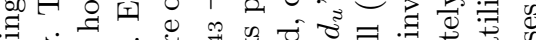

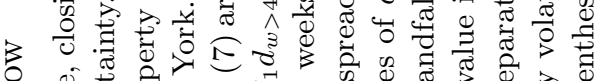
- 0 क क क

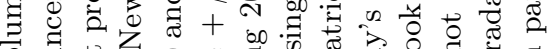

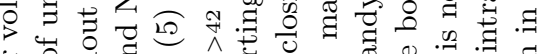
\% प

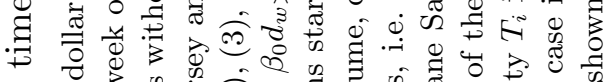

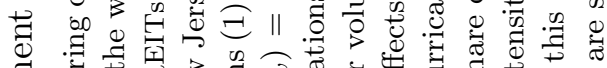

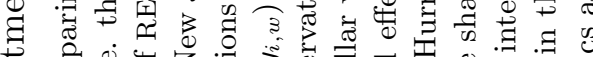

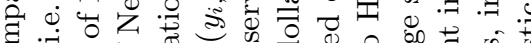

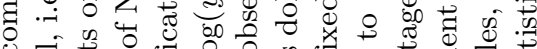

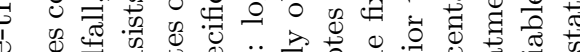

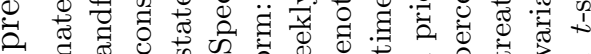

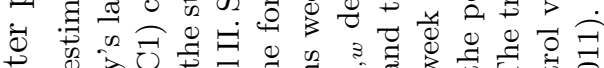

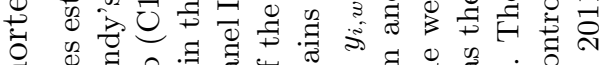

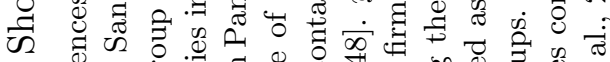

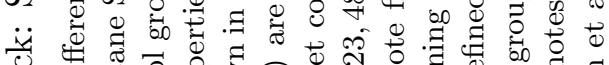

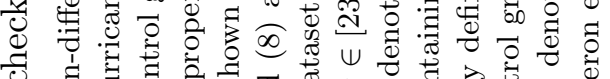

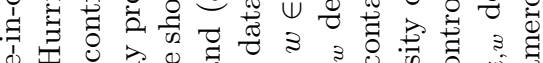

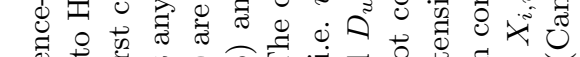

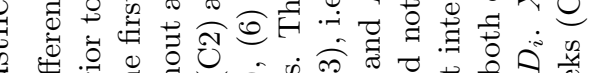

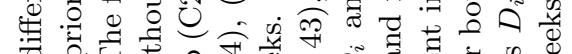
का

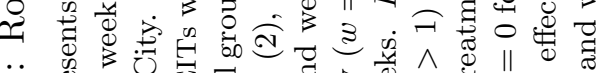
$\ddot{H}$

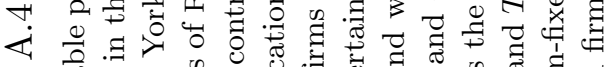

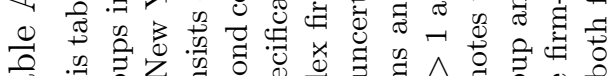

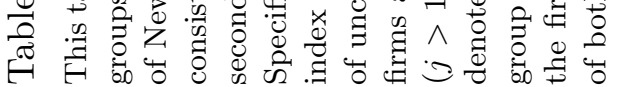

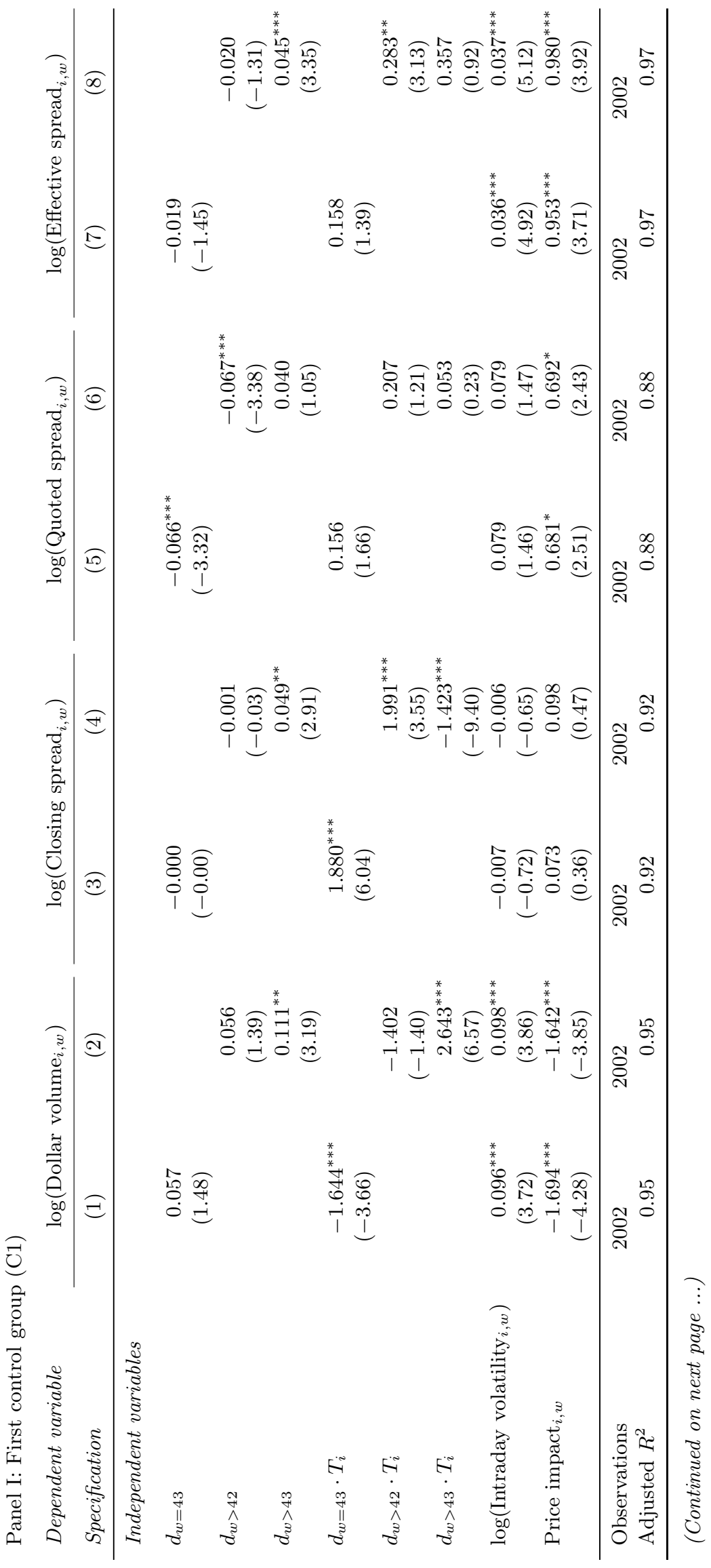




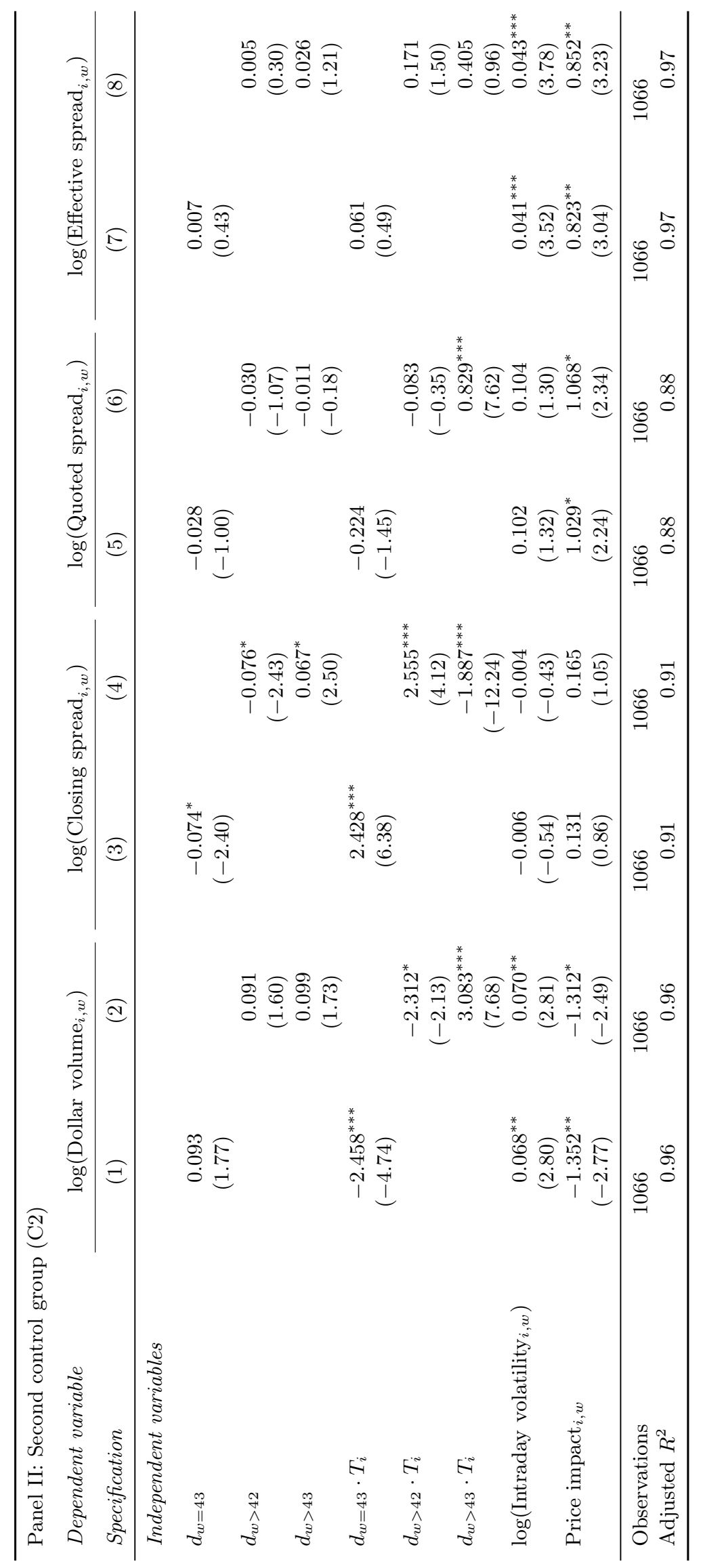




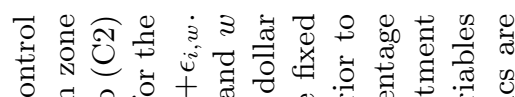

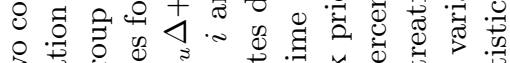

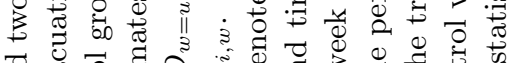

च

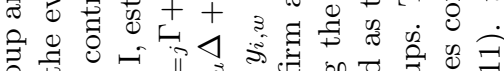

ప.t.

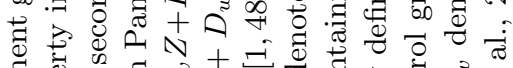

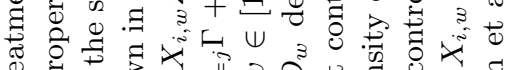

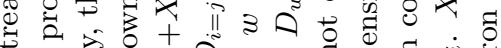

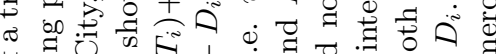

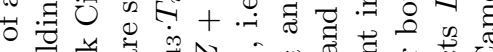

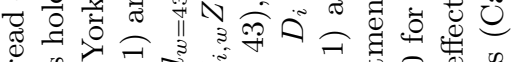

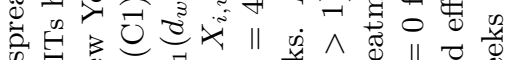

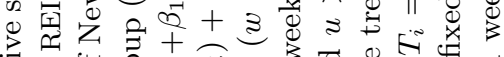

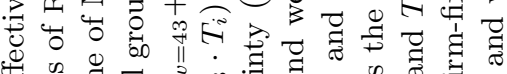

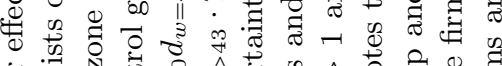

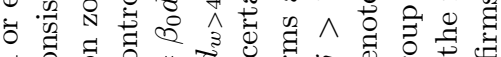

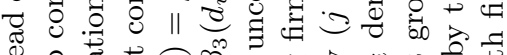

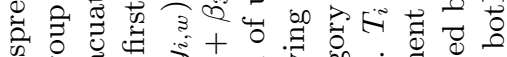

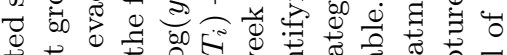

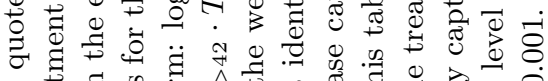

F

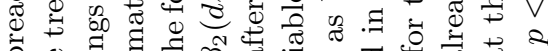

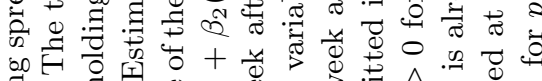

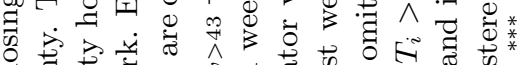

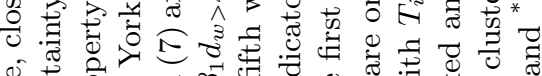

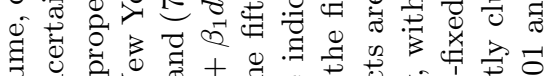

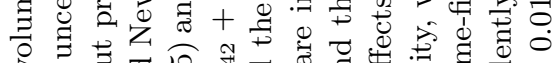

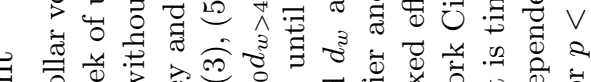

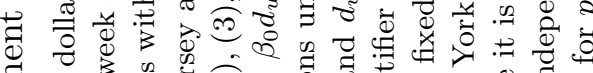

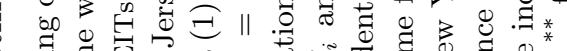

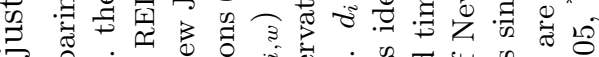

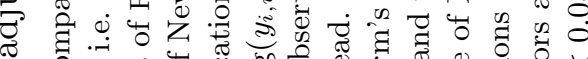

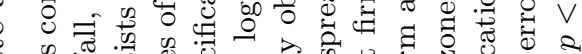

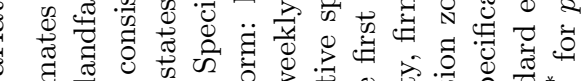

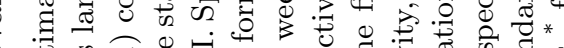

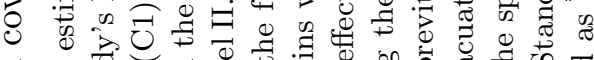

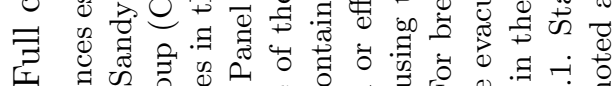

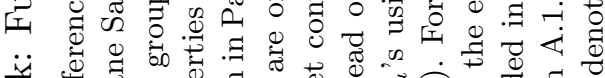

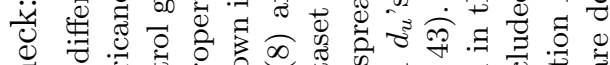

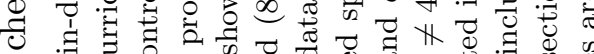

ब.

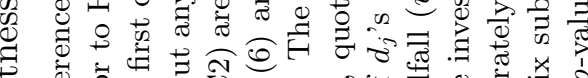

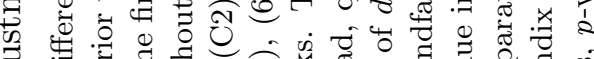

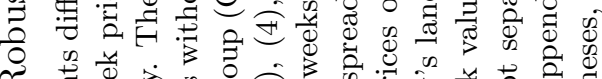

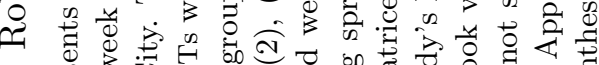

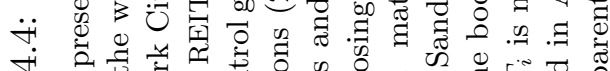

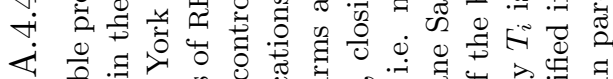

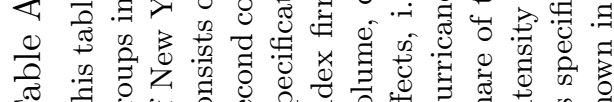

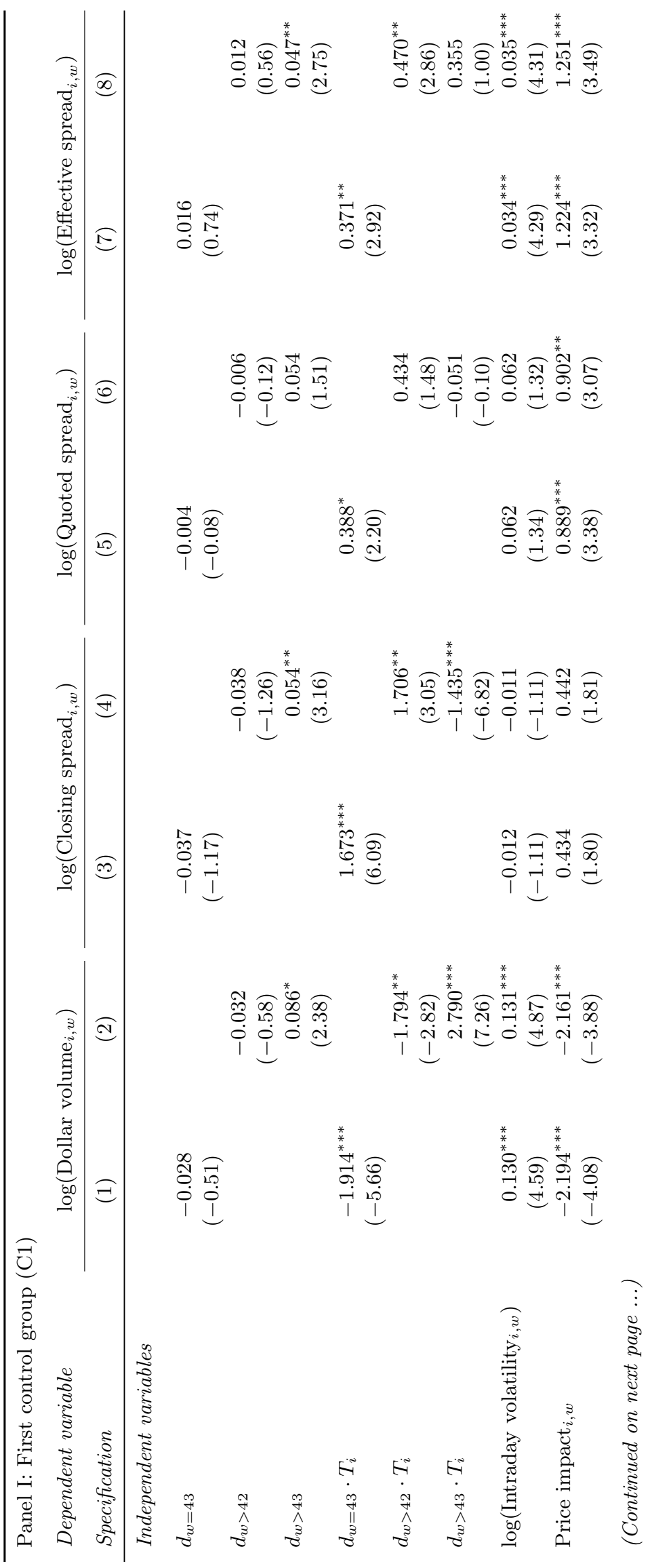




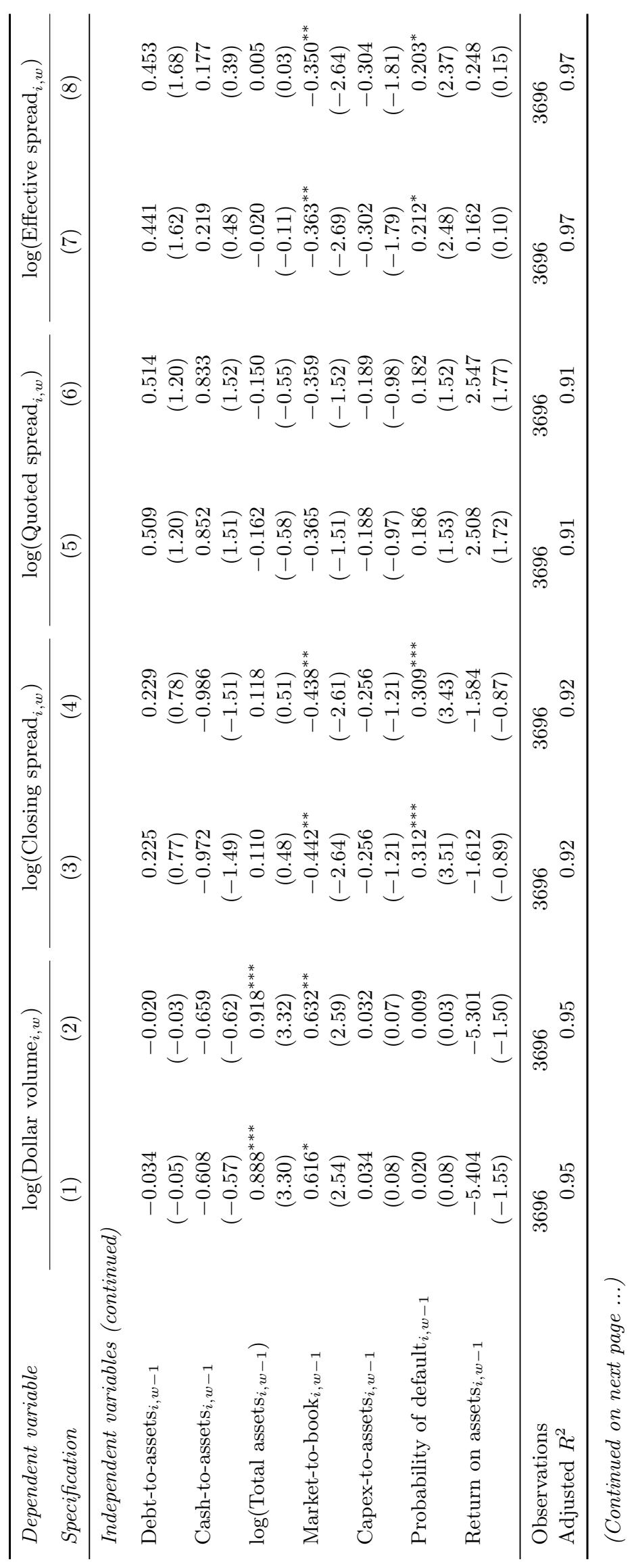




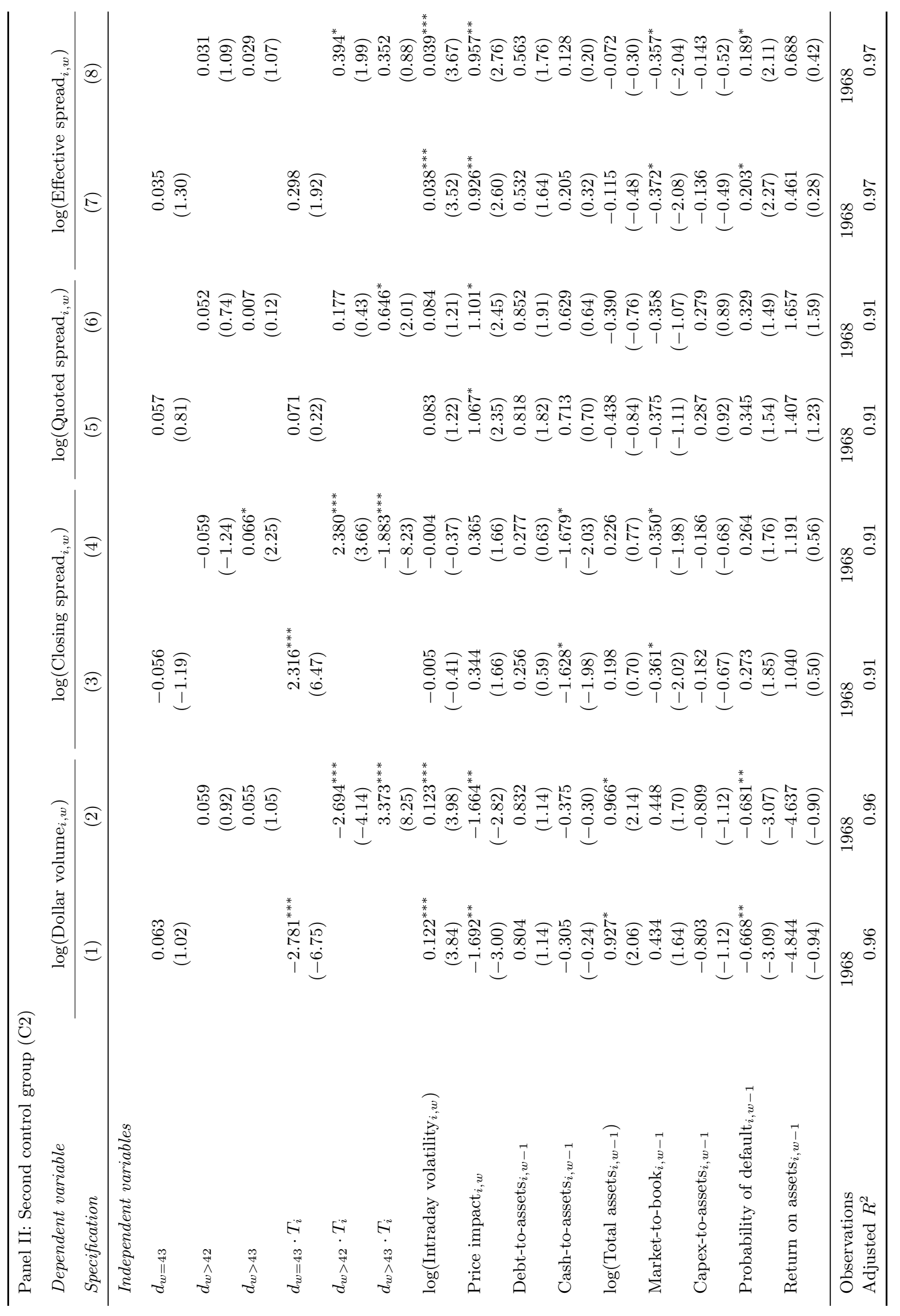




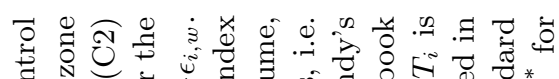

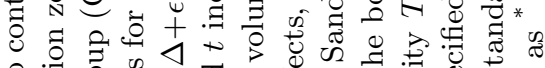

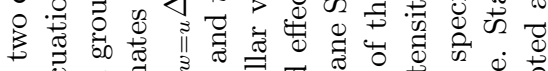

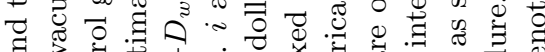
के

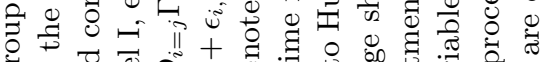
क.

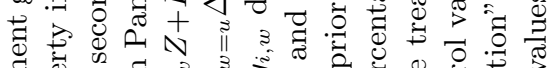
हैं 过

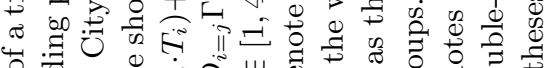

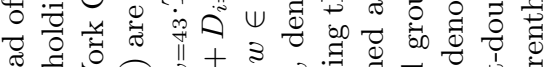

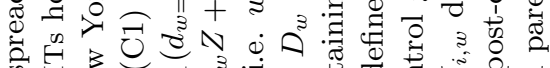

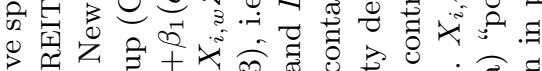

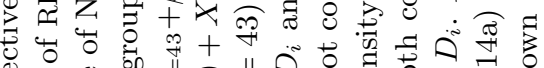

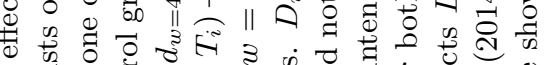
to चु ठ․

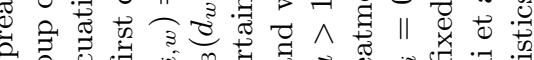
की

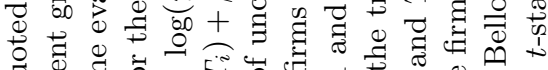

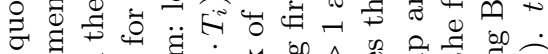

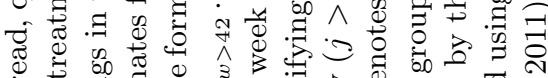

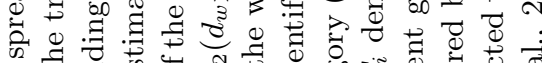
b0 स엉

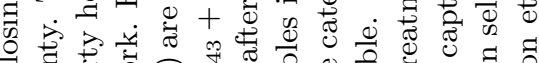

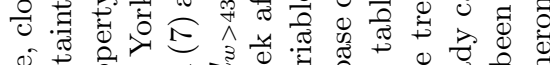

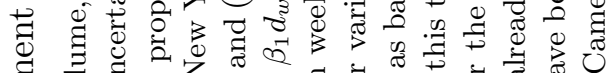

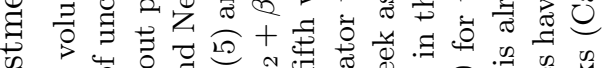

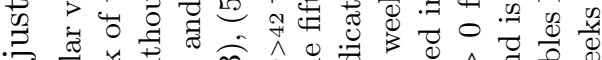
范

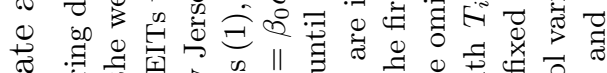
का है दे.

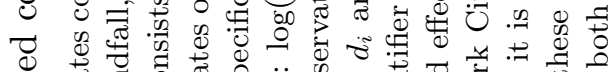

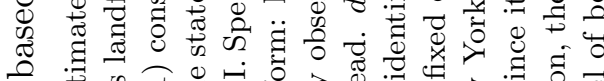
䓎 के $\exists$ 记

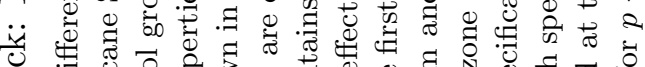

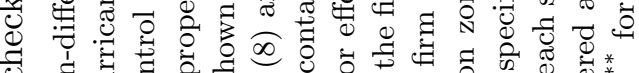

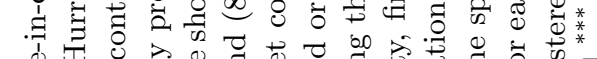

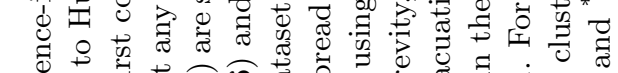

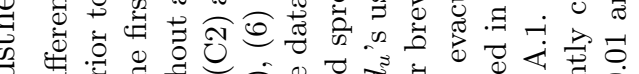

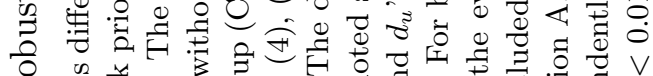

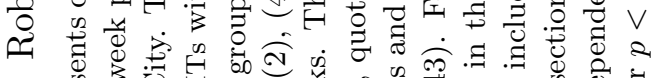
$\ddot{0} 0$ 군

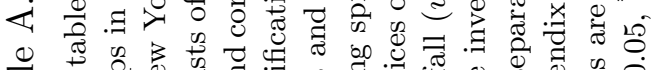
을

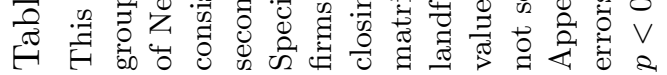

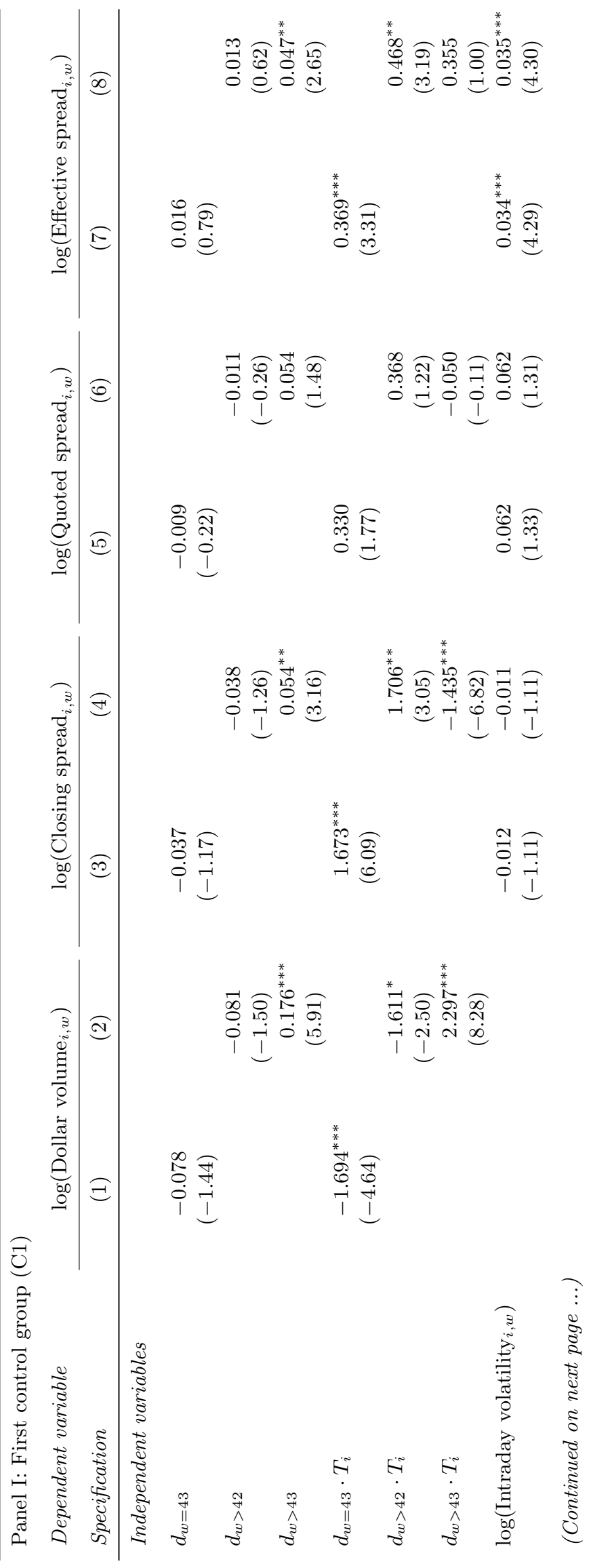




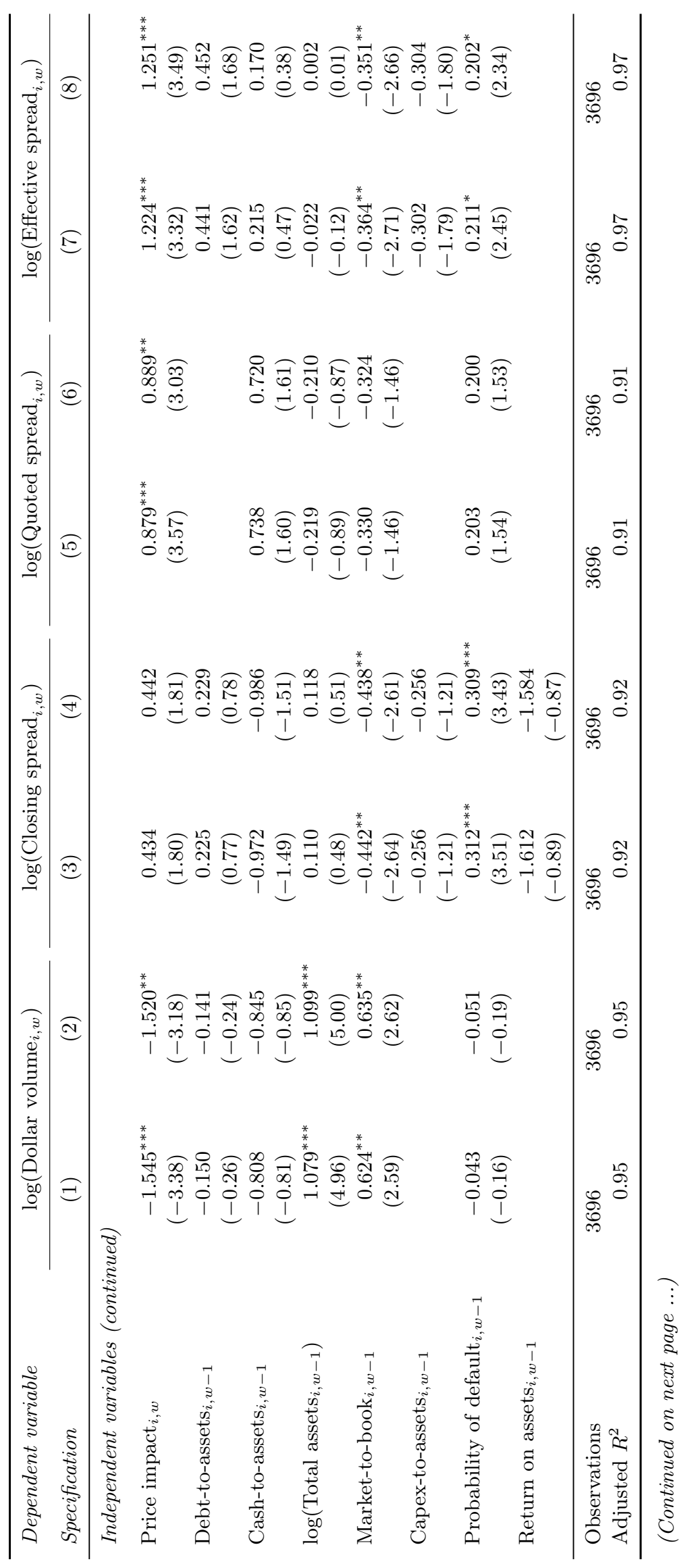




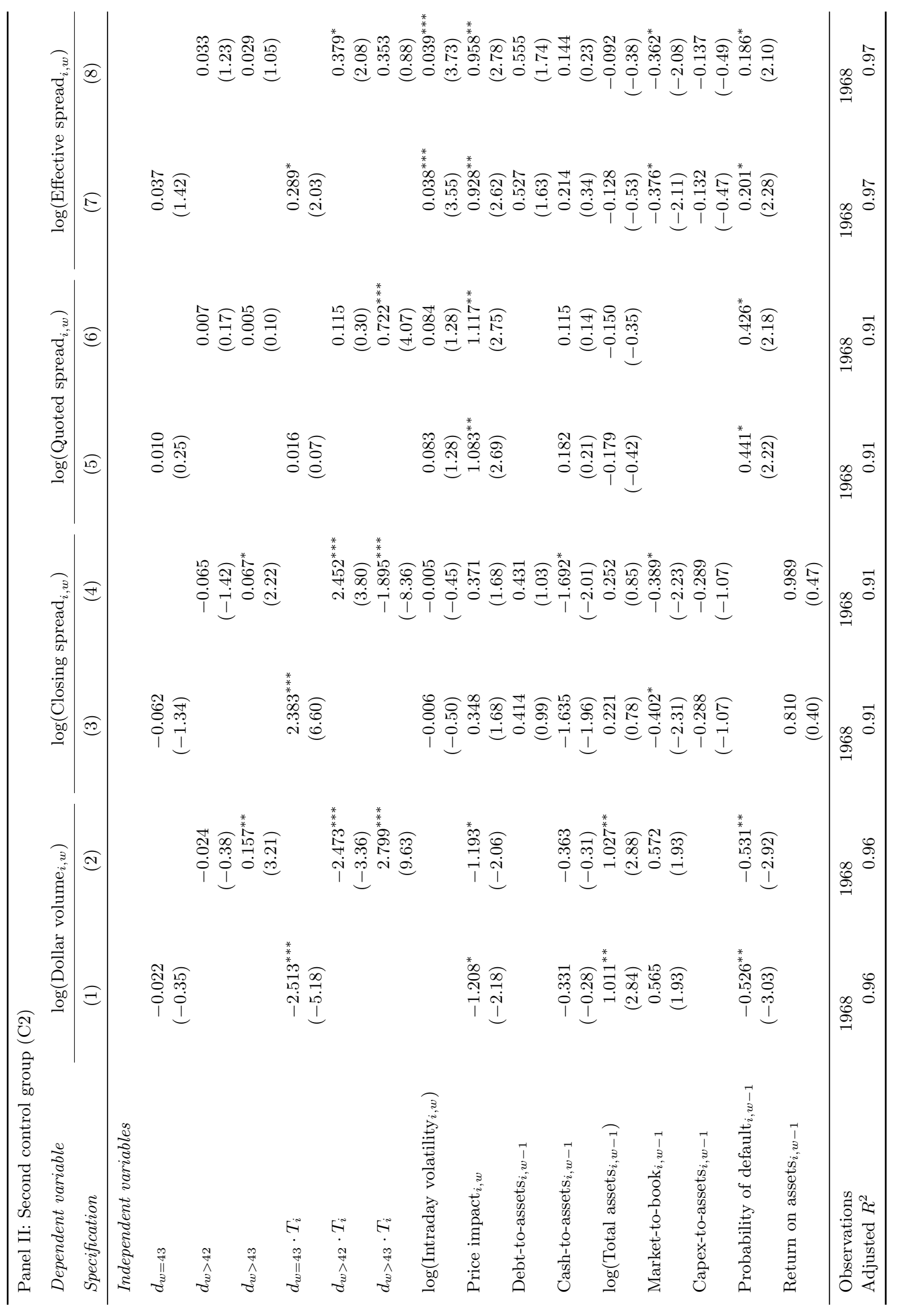

